\title{
The presubiculum is preserved from neurodegenerative changes in Alzheimer's disease
}

\author{
Christina E. Murray ${ }^{1,7}$, Priya Gami-Patel ${ }^{1}$, Eleni Gkanatsiou ${ }^{2}$, Gunnar Brinkmalm², Erik Portelius ${ }^{2,3}$, Oliver Wirths ${ }^{4}$, \\ Wendy Heywood ${ }^{5}$, Kaj Blennow ${ }^{2,3}$, Jorge Ghiso ${ }^{6}$, Janice L. Holton ${ }^{1}$, Kevin Mills ${ }^{5}$, Henrik Zetterberg ${ }^{2,3,7}$, \\ Tamas Revesz ${ }^{1}$ and Tammaryn Lashley ${ }^{1 *}$ (D)
}

\begin{abstract}
In the majority of affected brain regions the pathological hallmarks of Alzheimer's disease (AD) are $\beta$-amyloid (A $\beta$ ) deposits in the form of diffuse and neuritic plaques, tau pathology in the form of neurofibrillary tangles, neuropil threads and plaque-associated abnormal neurites in combination with an inflammatory response. However, the anatomical area of the presubiculum, is characterised by the presence of a single large evenly distributed 'lake-like' $A \beta$ deposit with minimal tau deposition or accumulation of inflammatory markers. Post-mortem brain samples from sporadic AD (SAD) and familial AD (FAD) and two hereditary cerebral amyloid diseases, familial British dementia (FBD) and familial Danish dementia (FDD) were used to compare the morphology of the extracellular proteins deposited in the presubiculum compared to the entorhinal cortex. The level of tau pathology and the extent of microglial activation were quantitated in the two brain regions in SAD and FAD. Frozen tissue was used to investigate the $A \beta$ species and proteomic differences between the two regions. Consistent with our previous investigations of FBD and FDD cases we were able to establish that the 'lake-like' pre-amyloid deposits of the presubiculum were not a unique feature of $\mathrm{AD}$ but they also found two non-A $\mathrm{B}$ amyloidosis. Comparing the presubiculum to the entorhinal cortex the number of neurofibrillary tangles and tau load were significantly reduced; there was a reduction in microglial activation; there were differences in the $A \beta$ profiles and the investigation of the whole proteome showed significant changes in different protein pathways. In summary, understanding why the presubiculum has a different morphological appearance, biochemical and proteomic makeup compared to surrounding brain regions severely affected by neurodegeneration could lead us to understanding protective mechanisms in neurodegenerative diseases.
\end{abstract}

Keywords: Alzheimer's disease, Presubiculum, Amyloid, Tau, Neuroinflammation

\section{Introduction}

The hippocampus and surrounding parahippocampal region are important for memory function and are severely affected early in Alzheimer's disease (AD) [2, 84]. The pathology observed in the hippocampus consists of marked neuronal loss, severe $\beta$-amyloid $(A \beta)$ plaque deposition, neurofibrillary tangle (NFT) formation and a neuroinflammatory reaction. However, one area within the parahippocampus, the presubiculum, appears to have a different pathological profile in comparison to other areas

\footnotetext{
*Correspondence: T.Lashley@ucl.ac.uk

'The Queen Square Brain Bank for Neurological Disorders, Department of Molecular Neuroscience, UCL Institute of Neurology, London WC1N 3BG, UK Full list of author information is available at the end of the article
}

of the medial temporal region $[2,36,37,84]$. In $\mathrm{AD}$, diffuse 'lake-like' $A \beta$ deposits appear in the presubiculum early in the disease process corresponding to Thal phases 2 and 3 with the morphology of the deposits not changing through to end stage disease, Thal stage 5 [74].

The hippocampus proper is formed from the dentate gyrus, the CA3/4, CA2, CA1 areas and the subiculum. The adjacent parahippocampal region is connected to the hippocampus via the perforant pathway $[4,10,79]$. The parahippocampus is made up of the pre- and parasubiculum, transsubiculum and entorhinal cortex [17]. It has been shown that the presubiculum has different pathological properties to the hippocampal formation in $\mathrm{AD}[2,37,84]$, in the form that the presubiculum 
contained a 'lake-like amyloid deposit' composed of $A \beta$ that filled the anatomical area instead of forming defined A $\beta$ plaques [37]. Thioflavin S and Congo-red staining, which highlight misfolded protein aggregates in an amyloid $\beta$-sheet conformational state, confirmed that the $A \beta$ deposited in the presubiculum was diffuse or pre-amyloid in nature $[2,75,84]$. A further number of observational differences were seen between the presubiculum and neighbouring hippocampal areas in that, only sparse NFTs, no activated glial cells and no amyloid-associated proteins such as apolipoprotein $\mathrm{E}$ or apolipoprotein $\mathrm{J}$ (clusterin) were detected [2, 36, 37, 84]. Conversely, the neighbouring entorhinal cortex had severe neuronal loss, dense core amyloid plaques, frequent NFT's, activated microglia and activated astrocytes $[2,36,37,84]$. These previous studies used silver impregnation techniques to identify the amyloid and NFTs together with semi-quantitative methods of analysis.

The amyloid plaques present in $\mathrm{AD}$ are composed of aggregated $A \beta$ peptides. $A \beta$ is formed from cleavage of the amyloid precursor protein (APP) and a number of different $A \beta$ peptide species are released due to secretases cleaving at different sites [11, 64, 71]. Whereas in the two hereditary neurodegenerative diseases, familial British dementia (FBD) and familial Danish dementia (FDD), both are characterised by extra-cellular amyloid and pre-amyloid deposits. In FBD a point mutation, while in FDD a decamer duplication insertion, abolishes the stop codon of the BRI2 gene [23, 30, 31, 77, 80, 81] resulting in elongated precursor proteins, from which the amyloid peptides amyloid-Bri (ABri) and amyloid-Dan (ADan) are released in FBD and FDD, respectively. Similar to $\mathrm{AD}$, there are numerous $\mathrm{ABri}$ and $\mathrm{ADan}$ amyloid plaques as well as diffuse plaques and also severe tau pathology in medial temporal lobe structures in both diseases, allowing for comparison with AD.

In this study we investigated whether the unique morphological appearance of deposited $A \beta$ in the presubiculum was protein-specific or due to different tissue factors found in the two different brain regions. To achieve these aims we investigated the morphological appearance of three amyloid forming extracellular peptides found in the presubiculum in SAD, FAD, FBD and FDD using immunohistochemical methods. To determine whether the presubiculum is protected against neurodegeneration and neuroinflammation, in SAD and FAD we quantitated the level of total tau pathology, the number of neurofibrillary tangles and levels of microglial activation compared to the neighbouring entorhinal cortex using immunohistochemical methods. We used laser capture microdissection paired with mass spectrometry to determine the $\mathrm{A} \beta$ peptide species that form the extracellular parenchymal deposits in the presubiculum compared to the amyloid plaques found in the entorhinal cortex in SAD and FAD. Laser capture microdissection teamed with label-free proteomics were used to identify altered protein expression or pathways that could be responsible for the differences between the presubiculum and entorhinal cortex.

\section{Material and methods \\ Cases}

All sporadic AD cases (SAD; $n=19)$ and familial AD cases (FAD; $n=11$ (8 PS1 and 3 APP mutations) were obtained through the brain donation program of the Queen Square Brain Bank for Neurological Disorders (QSBB), Department of Molecular Neuroscience, UCL Institute of Neurology. The FBD $(n=4)$ and FDD $(n=4)$ brains were donated to the QSBB, the Neuropathology Department, Århus Kommunehospital, Århus, Denmark or the Division of Neuropathology Department, UCL Institute of Neurology. The criteria for the neuropathological diagnosis of FBD and FDD have been previously described [30,31] while for that of AD standard diagnostic criteria were used $[9,52,74]$. The demographic data for all cases are shown in Table 1. Ethical approval for the study was obtained from the Local Research Ethics Committee of the National Hospital for Neurology and Neurosurgery.

\section{Immunohistochemistry}

Eight-micron-thick formalin-fixed paraffin-embedded tissue sections from the hippocampal/parahippocampal region, taken from the level of the lateral geniculate body, were cut from the cases listed in Table 1 . Sections were deparaffinised in xylene and rehydrated using graded alcohols. Immunohistochemistry for all antibodies required pre-treatment with a pressure cooker for $10 \mathrm{~min}$ in citrate buffer $\mathrm{pH}$ 6.0. $\mathrm{A} \beta, \mathrm{ABri}$ and $\mathrm{ADan}$ immunohistochemistry also required formic acid pre-treatment prior to pressure cooking. Endogenous peroxidase activity was blocked in $0.3 \% \mathrm{H}_{2} \mathrm{O}_{2}$ in methanol for $10 \mathrm{~min}$ and non-specific binding with $10 \%$ dried milk solution. Tissue sections were incubated with primary antibodies; $A \beta$ (1:100; Dako), $1-57$ N-terminal A $\beta_{\mathrm{pE} 3}$ (1:1000; Synaptic Systems), 2-48 N-terminal $\mathrm{A} \beta_{\mathrm{pE} 3}$ (1:100; Synaptic Systems), pE-A $\beta$ (1:200; Synaptic Systems), A $\beta-p E 11$ (1:100; Synaptic Systems), A $\beta 4-x$ (1:200; [83]); A $\beta 1-5$ (1:500; Synaptic systems 218,231), ABri (338; 1:1000), ADan (5282; 1:1000), AT8 (1:600; Thermo), Iba1 (1:1000; Wako), CD68 (1:100, DAKO), CR3-43 (1:150, DAKO), Annexin A1 (1:4000; Abcam), Annexin 2 (1:2000; Abcam), DOCK2 (1:100; Abcam) and INPPD5 (1:200; Proteintech) for $1 \mathrm{~h}$ at RT, followed by biotinylated anti-rabbit IgG (1:200; DAKO) or biotinylated anti-mouse IgG (1:200; DAKO) for $30 \mathrm{~min}$ at RT and Avidin-Biotin complex (30 min; Dako). Colour was developed with di-aminobenzidine $/ \mathrm{H}_{2} \mathrm{O}_{2}$ [42]. All antibodies were commercially available apart from anti-ABri 
Table 1 Demographics of cases used in the study

\begin{tabular}{|c|c|c|c|c|c|c|c|c|c|c|c|}
\hline Cases & $\begin{array}{l}\text { Disease } \\
\text { group }\end{array}$ & $\begin{array}{l}\text { Gene/ } \\
\text { Mutations }\end{array}$ & $\begin{array}{l}\text { Age at } \\
\text { onset }\end{array}$ & $\begin{array}{l}\text { Age at } \\
\text { death }\end{array}$ & $\begin{array}{l}\text { Disease } \\
\text { duration }\end{array}$ & Sex & $\begin{array}{l}\text { Post-mortem } \\
\text { delay (hours) }\end{array}$ & $\begin{array}{l}\text { Fixation time } \\
\text { (weeks) }\end{array}$ & $\begin{array}{l}\text { Braak and } \\
\text { Braak stage }\end{array}$ & Thal phase & $\begin{array}{l}\text { CERAD } \\
\text { score }\end{array}$ \\
\hline 1 & SAD & - & 63 & 73 & 10 & $M$ & 31 & 7.14 & 6 & 5 & Frequent \\
\hline 2 & SAD & - & 51 & 63 & 12 & $\mathrm{~F}$ & 16 & 4.00 & 6 & 5 & Frequent \\
\hline $3^{*}$ & $S A D$ & - & 51 & 62 & 11 & $\mathrm{~F}$ & 63 & 2.71 & 6 & 5 & Frequent \\
\hline 4 & SAD & - & 65 & 70 & 5 & $\mathrm{~F}$ & 47 & 4.29 & 5 & 5 & Moderate \\
\hline 5 & SAD & - & 64 & 77 & 13 & M & 90 & 3.14 & 6 & 5 & Frequent \\
\hline 6 & SAD & - & 49 & 62 & 13 & $\mathrm{~F}$ & 77 & 8.00 & 6 & 5 & Frequent \\
\hline 7 & SAD & - & 72 & 88 & 16 & M & 86 & 3.29 & 6 & 5 & Frequent \\
\hline 8 & SAD & - & 52 & 69 & 17 & M & 35 & 6.14 & 6 & 5 & Frequent \\
\hline 9 & SAD & - & 65 & 72 & 7 & M & 39 & 3.00 & 5 & 5 & Moderate \\
\hline 10 & SAD & - & 76 & 85 & 9 & $\mathrm{~F}$ & 90 & 3.86 & 6 & 5 & Frequent \\
\hline 11 & SAD & - & 55 & 64 & 9 & M & 77 & 3.43 & 6 & 5 & Frequent \\
\hline 12 & $S A D$ & - & 69 & 74 & 5 & F & 94 & 3.00 & 6 & 5 & Frequent \\
\hline 13 & SAD & - & 80 & 85 & 5 & M & 129 & $\mathrm{n} / \mathrm{a}$ & 5 & 5 & Moderate \\
\hline 14 & SAD & - & 46 & 52 & 6 & $F$ & 52 & 2.57 & 6 & 5 & Frequent \\
\hline 15 & SAD & - & 49 & 54 & 6 & $\mathrm{~F}$ & 48 & 4.29 & 6 & 5 & Frequent \\
\hline 16 & $S A D$ & - & 67 & 72 & 5 & M & 91 & 4.14 & 6 & 5 & Frequent \\
\hline 17 & SAD & - & 65 & 79 & 14 & $\mathrm{~F}$ & 23 & 3.43 & 6 & 5 & Frequent \\
\hline 18 & SAD & - & 52 & 68 & 16 & M & 35 & 3.00 & 6 & 5 & Frequent \\
\hline $19^{*}$ & SAD & - & 58 & 68 & 10 & M & 52 & 3.86 & 6 & 5 & Frequent \\
\hline \multicolumn{3}{|c|}{ SAD summary } & $60.5(10)$ & 70.4 (9.8) & $9.9(4.1)$ & $10 \mathrm{M}: 9 \mathrm{~F}$ & $61.8(30)$ & $4.1(1.5)$ & $5.8(0.4)$ & $5(0)$ & Frequent \\
\hline $20^{*}$ & FAD & PS1 Intron 4 & 35 & 52 & 17 & $\mathrm{~F}$ & 33 & $\mathrm{n} / \mathrm{a}$ & 6 & 5 & Frequent \\
\hline 21 & $\mathrm{FAD}$ & PS1 S132A & 61 & 70 & 9 & M & $\mathrm{n} / \mathrm{a}$ & 4.29 & 5 & 5 & Frequent \\
\hline 22 & $\mathrm{FAD}$ & PS1 Intron 4 & 42 & 51 & 9 & M & 43 & 4.00 & 6 & 5 & Frequent \\
\hline $23^{*}$ & $\mathrm{FAD}$ & APP V717 L & 48 & 59 & 11 & $\mathrm{~F}$ & 90 & $\mathrm{n} / \mathrm{a}$ & 6 & 5 & Frequent \\
\hline 24 & $\mathrm{FAD}$ & APP V7171 & 60 & 66 & 6 & M & 68 & 3.14 & 6 & 5 & Frequent \\
\hline 25 & $\mathrm{FAD}$ & PS1 A434T/ T291A & 42 & 47 & 5 & M & 44 & 4.29 & 5 & 5 & Frequent \\
\hline 26 & FAD & PS1 R278I & 46 & 66 & 20 & $\mathrm{~F}$ & 32 & 4.86 & 6 & 5 & Frequent \\
\hline 27 & $\mathrm{FAD}$ & PS1 I202F & 48 & 59 & 11 & $\mathrm{~F}$ & 26 & 4.00 & 6 & 5 & Frequent \\
\hline 28 & $\mathrm{FAD}$ & PS1 E120K & 33 & 37 & 4 & F & 24 & 6.00 & 6 & 5 & Frequent \\
\hline 29 & $\mathrm{FAD}$ & APP V7171 & 44 & 56 & 12 & $\mathrm{~F}$ & 16 & 4.29 & 6 & 5 & Frequent \\
\hline 30 & $\mathrm{FAD}$ & PS1 Intron 4 & 39 & 47 & 8 & $\mathrm{~F}$ & $\mathrm{n} / \mathrm{a}$ & $n / a$ & 6 & 5 & Frequent \\
\hline \multicolumn{3}{|c|}{ FAD summary } & $45.3(8.9)$ & $55.5(9.9)$ & $10.2(4.9)$ & $4 \mathrm{M}: 7 F$ & $53.7(43.7)$ & $4.4(0.8)$ & $5.8(0.4)$ & 5 & Frequent \\
\hline 31 & $\mathrm{FBD}$ & $B R / 2$ & 57 & 68 & 11 & $\mathrm{~F}$ & 6.5 & 3.00 & 5 & $n / a$ & $\mathrm{n} / \mathrm{a}$ \\
\hline 32 & $\mathrm{FBD}$ & $B R / 2$ & $\mathrm{n} / \mathrm{a}$ & 56 & $\mathrm{n} / \mathrm{a}$ & $\mathrm{F}$ & $\mathrm{n} / \mathrm{a}$ & $n / a$ & 5 & $\mathrm{n} / \mathrm{a}$ & $\mathrm{n} / \mathrm{a}$ \\
\hline 33 & $\mathrm{FBD}$ & $B R / 2$ & $\mathrm{n} / \mathrm{a}$ & 65 & $\mathrm{n} / \mathrm{a}$ & F & $\mathrm{n} / \mathrm{a}$ & $n / a$ & 5 & $n / a$ & $\mathrm{n} / \mathrm{a}$ \\
\hline 34 & $\mathrm{FBD}$ & $B R / 2$ & $\mathrm{n} / \mathrm{a}$ & 60 & $\mathrm{n} / \mathrm{a}$ & M & $\mathrm{n} / \mathrm{a}$ & $\mathrm{n} / \mathrm{a}$ & 5 & $\mathrm{n} / \mathrm{a}$ & $\mathrm{n} / \mathrm{a}$ \\
\hline \multicolumn{3}{|c|}{ FBD summary } & 57 & $62.3(5.3)$ & 11 & $1 \mathrm{M}: 3 \mathrm{~F}$ & 6.5 & 3.00 & 5 & $n / a$ & $n / a$ \\
\hline 36 & FDD & $B R / 2$ & 25 & 43 & 18 & M & $\mathrm{n} / \mathrm{a}$ & $\mathrm{n} / \mathrm{a}$ & 5 & $\mathrm{n} / \mathrm{a}$ & $\mathrm{n} / \mathrm{a}$ \\
\hline 37 & FDD & $B R / 2$ & 34 & 60 & 26 & F & $\mathrm{n} / \mathrm{a}$ & $\mathrm{n} / \mathrm{a}$ & 5 & $\mathrm{n} / \mathrm{a}$ & $\mathrm{n} / \mathrm{a}$ \\
\hline 38 & FDD & $B R / 2$ & 40 & 58 & 18 & M & $\mathrm{n} / \mathrm{a}$ & $\mathrm{n} / \mathrm{a}$ & 5 & $\mathrm{n} / \mathrm{a}$ & $\mathrm{n} / \mathrm{a}$ \\
\hline 39 & FDD & $B R / 2$ & 21 & 53 & 32 & M & $\mathrm{n} / \mathrm{a}$ & $n / a$ & 5 & $n / a$ & $\mathrm{n} / \mathrm{a}$ \\
\hline \multicolumn{3}{|c|}{ FDD summary } & $30(8.6)$ & $53.5(7.6)$ & $23.5(6.8)$ & $2 \mathrm{M}: 1 \mathrm{~F}$ & $n / a$ & $n / a$ & 5 & $n / a$ & $n / a$ \\
\hline
\end{tabular}

All cases were used for morphological analysis of the presubiculum. ${ }^{\prime * \prime}$ cases used for proteomics 
and anti-ADan which have been previously validated [30, 31]. Stained sections were digitised using a Leica slide scanner with a $40 \times$ objective.

\section{Thioflavin S immunofluorescence}

Sections from the hippocampal/parahippocampal region were cut from all cases and were incubated with $0.1 \%$ Thioflavin-S (Sigma) solution for $7 \mathrm{~min}$. The sections were differentiated in $70 \%$ ethanol and washed in Tris-buffered-saline. The standard immunohistochemistry protocol was applied to the sections to stain for $A \beta$, ABri and ADan, replacing di-aminobenzidine with TSA plus TMR system (Perkin Elmer) to provide the fluorescent signal. Sections were viewed with a Leica TCS4D confocal microscope using a 3-channel scan head and argon/krypton laser.

\section{Laser capture microscopy}

To investigate differences in the $A \beta$ species profile between the presubiculum and entorhinal cortex in the AD cases, ten-micron-thick frozen tissue sections were sampled from the hippocampal/parahippocampal region at the level of the lateral geniculate body from SAD cases (cases 3 and 19) and FAD cases (case 20 (PS1 mutation) and case 23 (APP mutation)) (highlighted in Table 1). Sections were mounted onto PEN-membrane slides (Leica) coated with polyethylene naphthalate, fixed with $4 \%$ paraformaldehyde (PFA), and treated in formic acid for 5 min before the immunohistochemistry protocol for $A \beta$ was performed. The Leica DM6000B laser capture microdissection (LCM) microscope was used to firstly dissect the $A \beta$-positive areas of the presubiculum from three sections per each case (average area per case $1.6 \mu^{2}$ ) and 300 amyloid plaques (average area per case $2.0 \mu \mathrm{m}^{2}$ ) from the neighbouring entorhinal cortex. Samples were collected from both regions for matrix-assisted laser desorption/ionization-time-of-flight (MALDI-TOF) mass spectrometric analysis to identify the A $\beta$ peptides present in both brain regions. Samples were also collected from both brain regions via LCM to investigate the whole proteome.

\section{Mass spectrometry}

To identify the $A \beta$ peptides in the laser-captured presubiculum lesions and amyloid plaques from entorhinal cortex samples were aspirated with $70 \%$ formic acid, centrifuged and aspirated again. Samples were vortexed and dried before being resuspended in $5 \mu \mathrm{l} 0.1 \% \mathrm{FA} / 20 \%$ acetonitrile (ACN). To prepare the matrix, $0.5 \mu \mathrm{l}$ of the seedlayer (20 g/L $\alpha$-cyano-4-hydroxycinnamic acid (CHCA) in $90 \%$ acetone $/ 10 \%$ methanol with $0.005 \%$ trifluoroacetic acid [TFA]) was added to the probe. An aliquot sample $(2 \mu \mathrm{l})$ was mixed with $1 \mu \mathrm{l}$ sample matrix [15 g/L CHCA] in $\mathrm{ACN}$ and $0.1 \%$ TFA [1:1]) before being placed on the probe. The different $A \beta$ peptides in each sample were determined using MALDI-TOF-MS [56].

To investigate the proteome in the laser-captured presubiculum and entorhinal cortex, samples were homogenised in $50 \mathrm{mM}$ Ambic buffer with 2\% ASB-14 using the Precellys 24 homogenizer (Bertin Instruments). The total protein concentration was determined by $\mathrm{BCA}$ protein assay (Thermofisher). Due to the low amount of protein present in the laser captured material samples had to be pooled. A sample pool of each disease group was created with equal protein concentration from each case. Samples were fractionated to look at soluble and insoluble proteins. Samples were spun at maximum speed for ten minutes at $4{ }^{\circ} \mathrm{C}$ and the supernatant containing the soluble proteins was removed. The remaining pellet was resuspended in ice cold acetone, vortexed and left at $-20{ }^{\circ} \mathrm{C}$ for at least an hour. Samples were vortexed and spun at $14000 \mathrm{~g}$ for ten minutes at $4{ }^{\circ} \mathrm{C}$, the supernatant was removed. The pellets containing the insoluble proteins were air-dried and re-suspended in 70\% formic acid and vortexed and dried in a speed-vac. Ice-cold acetone was added to the original soluble protein supernatants and left at $-20{ }^{\circ} \mathrm{C}$ overnight. The supernatants were vortexed and spun at $14000 \mathrm{~g}$ for ten minutes at $4{ }^{\circ} \mathrm{C}$. The supernatant was removed and the remaining pellet was dried. Dried supernatants and pellets were reconstituted in $100 \mathrm{mM}$ Tris/8 M Urea/2\% ASB-14, pH 7.79, vortexed and left shaking for one hour to resolubilise the proteins. Dithioerythritol (30 $\mathrm{mg} / \mathrm{ml}$, Sigma) was added, vortexed and left shaking for a further hour as a reducing agent. To prevent the formation of disulphide bonds iodoacetamide $(36 \mathrm{mg} / \mathrm{ml}$, Sigma) was added to alkylate the proteins, before the addition of $\mathrm{H}_{2} \mathrm{O} .1 \mu \mathrm{g}$ Trypsin-LysC enzyme (Promega Trypsin/Lys-C Mix, Mass Spec Grade cat no. V5073) was added to digest the proteins and was left for three-four hours at $37^{\circ} \mathrm{C}$. The digested samples were diluted 1:1 in $0.2 \%$ TFA and 5 pmol of Waters MassPREP enolase digestion standard (part no. 186002325) was added to the digest. Peptides were cleaned in Agilent C18 Bond Elut 96 well plates (Part no. A496011C). The wells were primed with $50 \%$ ACN $/ 0.1 \%$ TFA and then washed twice with $0.1 \%$ TFA. The diluted digest samples were added to the wells and allowed to drip through. The residual salts were washed away using 3\% ACN/0.1\% TFA and peptides eluted using $2 \times 50 \% \mathrm{ACN} / 0.1 \%$ TFA.

The digested cleaned peptides were reconstituted in $3 \%$ ACN/0.1\% TFA. MS ${ }^{\mathrm{e}}$ Label-free mass spectrometry was performed as previously described [6] with a SYNAPT G2-Si High Definition machine with 2D fractionation. Four fractions were run for each sample and $0.5 \mu \mathrm{g}$ of protein was injected per fraction per run. The order of samples were randomised to avoid technical bias. The raw data was processed using Progenesis QI for proteomics (Nonlinear Dynamics, UK). Peptides were identified with an $\mathrm{MS}^{\mathrm{e}}$ 
search against the UniProt reviewed human proteome with the following parameters: missed cleavages, max one; max protein mass, 800,000 kDa; modifications of carbamidomethyl $\mathrm{C}$, oxidation $\mathrm{M}$, demidation $\mathrm{N}$ and $\mathrm{Q}$. The ion matching requirements were set as follows: three fragments/peptide, five fragments/protein, one peptide/ protein. Proteins that had been identified with only one unique peptide were excluded from the analysis. Protein identification and normalised abundance was exported into excel for further bioinformatics.

\section{Bioinformatics}

Proteins that had $>1.5$-fold change in expression between regions were put into publicly available databases to assess the biological processes, molecular functions and cell components that were enriched in each region. Webgestalt was used to assess the enriched gene ontology terms [87].

\section{Morphological analysis}

Sequential sections were immunohistochemically stained for A $\beta$, AT8, Iba1, CD68 and CR3-43. Sections stained with $A \beta$ were used to identify the 'lake-like' deposit in the presubiculum and entorhinal cortex in each case. Bland-Altman plots were used to determine the intraand inter-rater reliability for the number of randomized snapshot areas required for the quantitation of the different immunohistochemical preparations [5]. Using Image J software (https://imagej.net/) and setting the threshold to include only di-aminobenzidine staining, twenty randomised snapshots from an identified region of interest, each measuring $1500 \mu \mathrm{m} \times 1000 \mu \mathrm{m}$, were generated, using a python script, from the pre-marked presubiculum and the entorhinal cortex. Images were captured using Leica Image scope. The twenty snapshots were then used to determine the mean 'areal fraction' for each immunohistochemical preparation, defined by the ratio of the area occupied by positive immunohistochemical staining and the field of interest [25]. Iba1, CD68 and CR3-43 immunohistochemical preparations were used for the assessment of the microglial response while AT8 immunohistochemistry was employed to determine the phosphorylated tau load, comprising NFTs, neuropil threads (NTs) and plaque-associated abnormal neurites. In addition, the number of NFTs, identified as large filamentous tau-positive structures in the neuronal cytoplasm [57], were also determined in both the presubiculum and entorhinal cortex. NFTs were systematically counted with any partial NFTs being excluded.

\section{Statistical analysis}

Statistical analysis was performed using GraphPad Prism 5 software (GraphPad Software Inc. USA). Continuous variables were analysed using either a two-tailed $t$-test or a Mann-Whitney U test, as appropriate while continuous variables between several groups were compared using the Kruskal-Wallis test. The statistical significance level was established at $p<0.05$.

\section{Results}

Comparison of the pathological characteristics in the presubiculum and entorhinal cortex in AD, FDB and FDD

The pathology observed in the presubiculum was morphologically different from that in the entorhinal cortex in all cases of SAD and FAD investigated (Fig. 1). In the presubiculum $A \beta$ deposited as hazy, diffuse 'lake-like' lesions in the parenchyma (Fig. $1 \mathrm{a}$ and d arrows and $1 \mathrm{~b}$ and 1 e, higher magnification) whereas large numbers of 'mature' A $\beta$ amyloid cored plaques with well-defined edges were present in the entorhinal cortex (Fig. 1c and f). A similar difference in the morphology of the parenchymal deposits between these two anatomical areas was observed in two other cerebral amyloid diseases, FBD and FDD. Accordingly diffuse, 'lake-like' ABri and ADan deposits were seen in the presubiculum (Fig. $1 \mathrm{~g}$ and $\mathrm{j}$, arrows, shown at higher magnification Fig. $1 \mathrm{~h}$ and $\mathrm{k}$ ) and well-defined amyloid plaques in the entorhinal cortex (Fig. 1i and l) of FBD and FDD, respectively.

$\mathrm{A} \beta$, ABri or ADan immunohistochemistry combined with Thioflavin-S staining revealed that the extracellular proteins found in the lake-like peptide deposits of the presubiculum (Fig. 2b, arrow) were Thioflavin-S negative in all cases (Fig. 2c) indicating that such deposits were of pre-amyloid nature in both SAD and FAD. In contrast, the plaque-like lesions of the entorhinal cortex were positive for both $A \beta$ (Fig. 2e) and Thioflavin $S$ (Fig. 2f) indicative of amyloid conformation of the $A \beta$ species.

\section{Tau deposition and NFT frequency in FAD and SAD}

The phosphorylated tau load comprising all tau-positive lesions was significantly greater in the entorhinal cortex compared to the presubiculum in both SAD $(p<0.0001)$ and FAD $(p=0.001)$ (Table 2 ; Figs. $2 \mathrm{~h}, 1$ and 3$)$. Furthermore, there were significantly more NFTs in the entorhinal cortex compared to the presubiculum in both AD groups (SAD: $p<0.0001$; FAD: $p=0.001$ ) (Table 2; Figs. 2h, 1 and 3).

\section{Microglial activation in FAD and SAD}

Neuroinflammation is a prominent feature of neurodegenerative diseases. In this study we assessed the extent of neuroinflammatory response by determining the density of three microglia markers in the presubiculum and entorhinal cortex. The Iba1 marker, a calcium binding protein that detects total numbers of microglia, was used to assess any homeostatic microglia present $[8,69]$. The CD68 and CR343 antibodies both detect activated microglia, phagocytic microglia and antigen presenting microglia, respectively $[8,39]$. The density of the resident microglia, as detected 

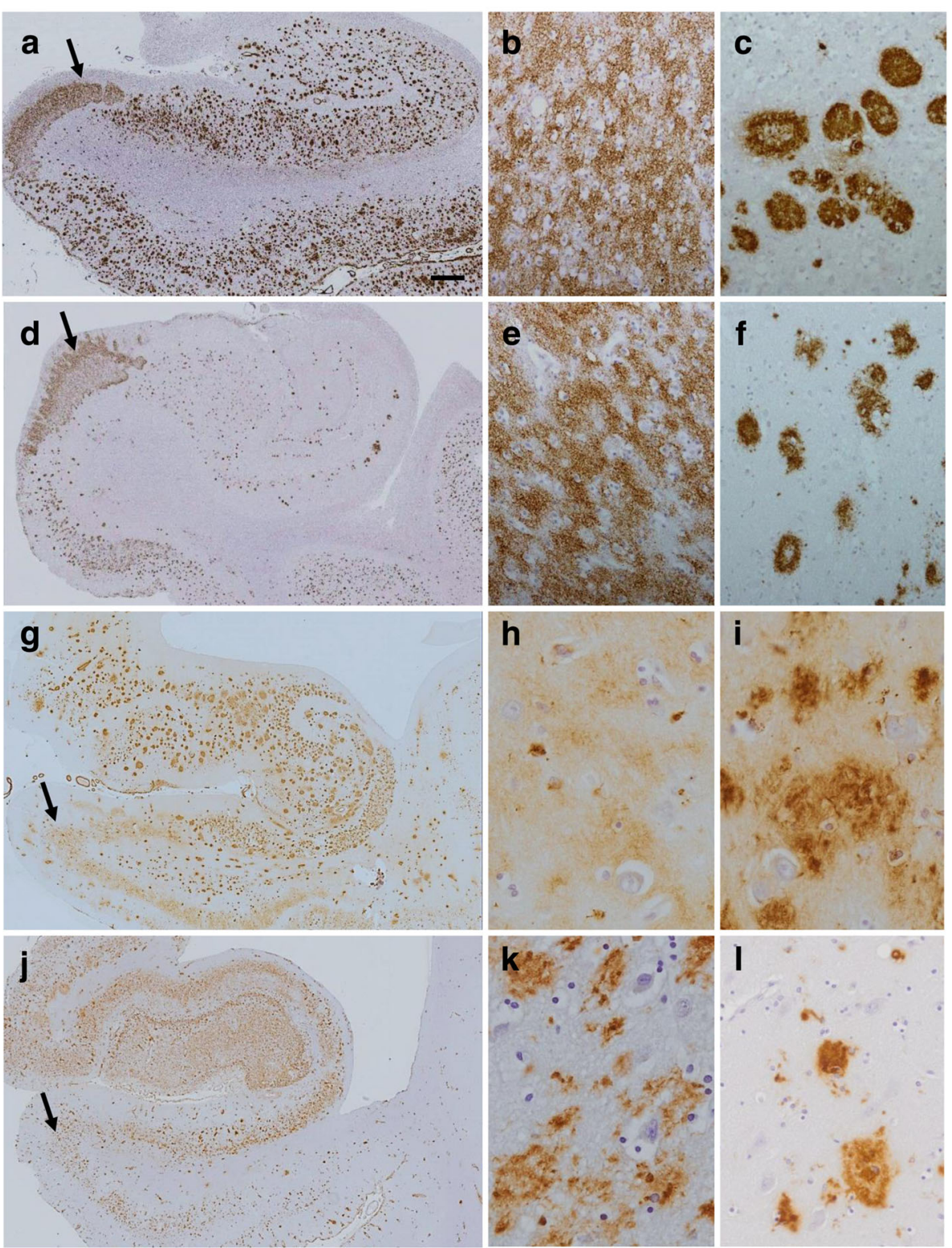

Fig. 1 Pathological analysis of the presubiculum in familial and sporadic Alzheimer's disease (AD; a-f), familial British dementia (FBD; $\mathbf{g}$-i) and familial Danish dementia (FDD; $\mathbf{j}-\mathbf{I})$. A immunohistochemistry demonstrates large diffuse, 'lake-like' deposits in the presubiculum in both familial $\mathrm{AD}$ (case 26; $\mathbf{a}$, arrow; $\mathbf{b}$, presubiculum at higher magnification) and sporadic $\mathrm{AD}$ (case 2; $\mathbf{d}$, arrow; e presubiculum at higher magnification). In both disease types well-defined A $\beta$ plaques were present in the entorhinal cortex as shown in sporadic AD (c and f). The ABri-positive (case 31; $\mathbf{g}$-i) and ADan-positive (case 36; $\mathbf{j - I}$ ) parenchymal deposits show similar morphological patterns in FBD and FDD, respetively. Bar in a represents $1000 \mu \mathrm{m}$ in $\mathbf{a}, \mathbf{d}, \mathbf{g}$, and $\mathbf{j} ; 50 \mu \mathrm{m}$ in all remaining images

by Iba1 immunohistochemistry, was similar in the presubiculum and the entorhinal cortex in FAD $(p=0.92)$ (Table 2). Whereas a similar analysis in SAD showed that more microglia were present in the presubiculum than in the entorhinal cortex $(p=0.03)$ (Table 2; Figs. $2 \mathrm{i}, \mathrm{m}$ and 4). However, CD68 $(p<0.0001$ and $p=0.02$ in SAD and FAD respectively) and CR3-43 ( $p=0.0003$ and $p=0.02$ in $\mathrm{SAD}$ and $\mathrm{FAD}$ respectively) preparations showed that the area density of the microglia was significantly reduced in the presubiculum compared with the entorhinal cortex in both the SAD and FAD groups (Table 2; Figs. 2j-o and 4).

\section{Identification of $A \beta$ species in $F A D$ and $S A D$}

LCM and MALDI-TOF-MS were utilised to examine whether the biochemical profile of the $A \beta$ species found 


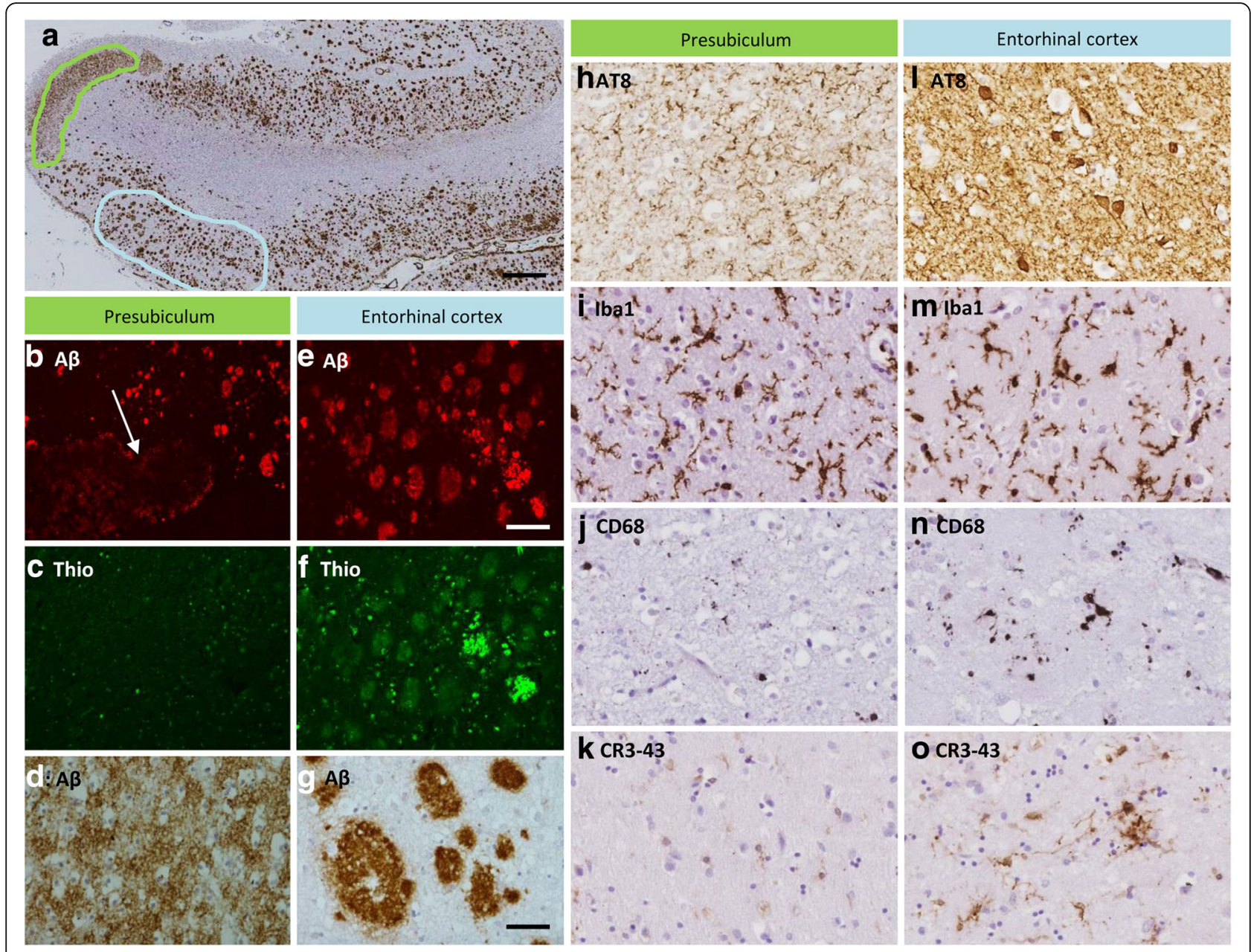

Fig. 2 Pathological comparisons of the presubiculum and entorhinal cortex in Alzheimer's disease. The image demonstrates the anatomy of the hippocampus and illustrates the difference in $A \beta$ deposition between the presubiculum (green outline) and entorhinal cortex (blue outline). Fluorescent $A \beta$ immunohistochemistry shows that the $A \beta$ peptide is deposited in a diffuse manner in the presubiculum ( $\mathbf{b}$, white arrow) whereas defined $A \beta$ plaques are shown in the entorhinal cortex (e). Thioflavin $S$ staining highlights the $A \beta$ plaques in the entorhinal cortex (f), whereas the presubiculum is negative for the Thioflavin $S$ stain demonstrating the $A \beta$ in the presubiculum contains pre-amyloid deposits (c). Tau immunohistochemistry shows a difference between the presubiculum (h) and entorhinal cortex (I) in the density of neuropil threads and neurofibrillary tangles. The microglial marker, Iba1, shows the total number of microglia being equal between the two regions (I and $\mathbf{m}$ ), whereas CD68 and CR3-43 highlight the increase in the number of activated microglia in the entorhinal cortex ( $\mathbf{n}$ and $\mathbf{o}$ ) compared to the presubiculum ( $\mathbf{j}$ and $\mathbf{k}$ ). Bar in 'a' represents $1000 \mu \mathrm{m}$ in $\mathbf{a}$; $100 \mu \mathrm{m}$ in $\mathbf{b}, \mathbf{c}$, e, and $\mathbf{f} ; 50 \mu \mathrm{m}$ in $\mathbf{d}$, $\mathbf{g}$ and $\mathbf{h}-\mathbf{o}$

in the presubiculum were different from species present in amyloid plaques isolated from the entorhinal cortex. These studies showed no difference in the profile of the $\mathrm{A} \beta$ peptide species between the SAD and FAD cases (Fig. 5). Full length $A \beta_{1-42}$, numerous $\mathrm{N}$-terminally truncated peptides and post-translationally modified peptide $A \beta$ species with pyroglutamate at positions 3 or 11 were identified in the entorhinal cortex. This was in contrast to the $A \beta$ peptides identified in the presubiculum where full length $\mathrm{A} \beta_{1-42}$ and the $\mathrm{N}$-terminally truncated $\mathrm{A} \beta_{4-42}$ were identifed. No pyroglutamate post-translationally modified $A \beta$ species were identified in the presubiculum in either SAD or FAD (Fig. 5). To validate the differences in $A \beta$ species present in the entorhinal cortex compared to the presubiculum immunohistochemical methods utilising antibodies raised against $\mathrm{N}$-terminally truncated and pyroglutamate modified $A \beta$ species were employed. All antibodies (1-57 N-terminal $\mathrm{A} \beta_{\mathrm{pE} 3}, 2-48 \mathrm{~N}$-terminal $\left.A \beta_{p E 3}, p E-A \beta, A \beta-p E 11, A \beta 4-x, A \beta 1-x\right)$ labelled the $A \beta$ plaques in the entorhinal cortex and some degree of positve staining in the presubiculum was observed (Fig. 6a-f). Positive immunohistochemical staining for these $A \beta$ species in the presubiculum indicates that the $A \beta$ peptides are present in the presubiculum but the amount may differ between the two regions, making them undetectable by MALDI-TOF MS or that the 


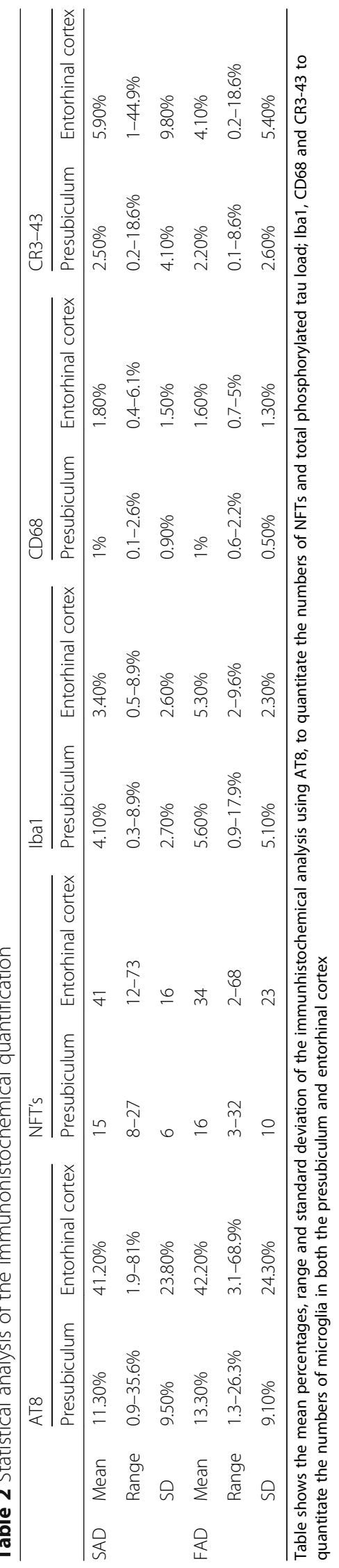




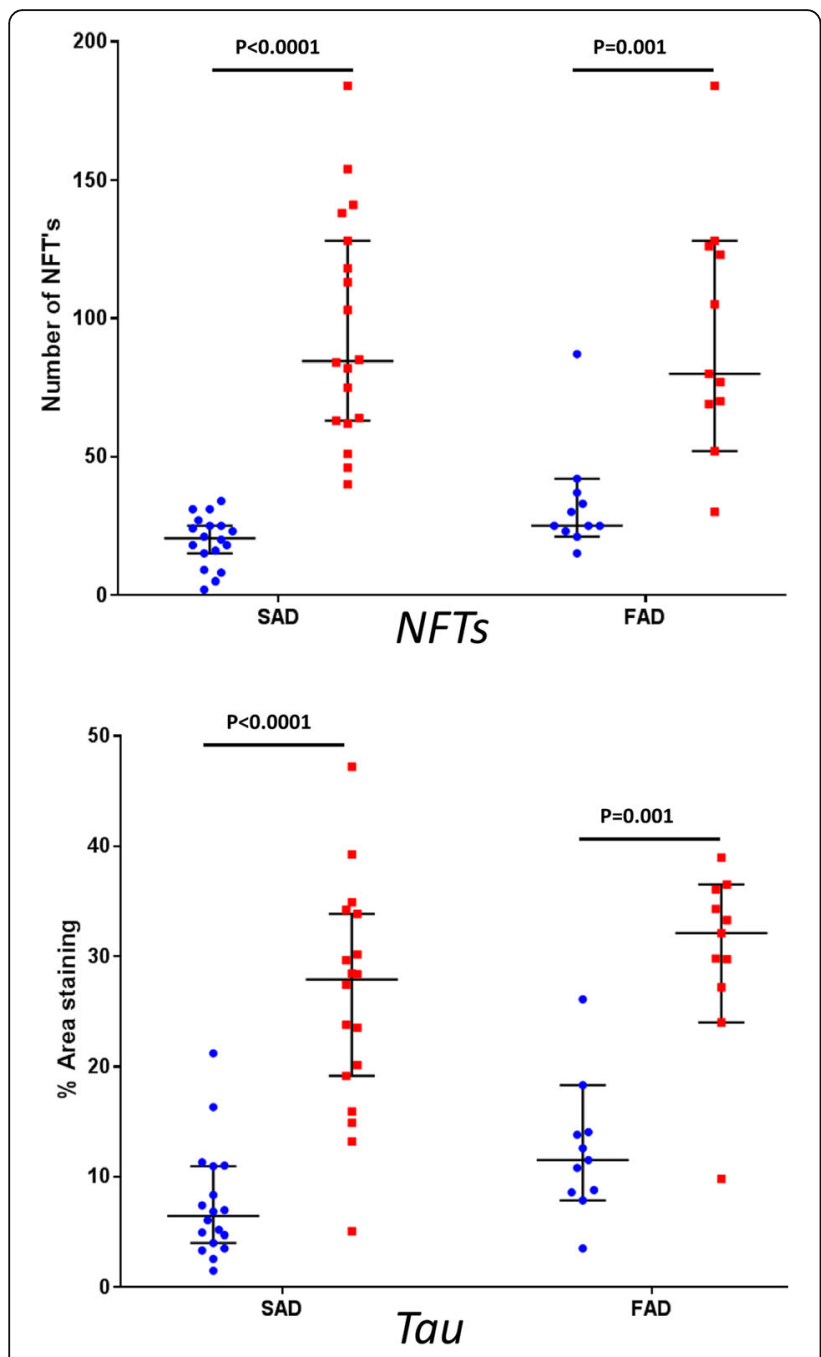

- Presubiculum

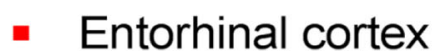

Fig. 3 Quantification of microglial immunohistochemistry in the presubiculum and entorhinal cortex. The overall numbers of microglia were similar in the two anatomical areas as shown by the Iba1. However the presubiculum had significantly less activated microglia, positive for CD68 and CR3-43, than the entorhinal cortex in both sporadic and familial AD cases. FAD; Familial Alzheimer's disease: SAD; Sporadic Alzheimer's disease. Bars represent medians with $95 \%$ confidence intervals. Wilcoxon paired rank test was performed in each case and $p$ values are shown

species specific antibodies might show some minor cross-reactivity with other $A \beta$ species (e.g. unmodified A $33-42)$ [85].

Proteomic expression in the presubiculum in FAD and SAD We investigated alterations in protein expression in the presubiculum compared to the entorhinal cortex using $\mathrm{MS}^{\mathrm{e}}$ label free proteomics. Samples were analysed as soluble protein supernatant and insoluble protein pellet fractions with a total of 561 proteins detected in the supernatant and 1824 proteins in the pellet. Some proteins were detected in both fractions (303 proteins) or only in one (supernatant 254 proteins, pellet 1488 proteins). SAD cases were pooled into one sample and FAD cases pooled into another. Due to pooling the samples, statistics could not be undertaken, instead fold change between regions was determined to highlight the greatest changes occurring. The fold change expression was calculated for each protein for the presubiculum compared to the entorhinal cortex. SAD and FAD cases were analysed separately and additionally, an average fold change between both was calculated. When analysing the average fold change between SAD and FAD, a total of 112 proteins had an increased fold change of 1.5 or greater in the presubiculum compared to the entorhinal cortex in the supernatant and 313 in the pellet (Additional file 1: Table S1 and Additional file 2: Table S2). Proteins were also found to be decreased in the presubiculum compared to the entorhinal cortex in the supernatant (130 proteins) and the pellet (703 proteins) (Additional file 3: Table S3 and Additional file 4: Table S4). Several proteins were markedly increased in the presubiculum or entorhinal cortex at a level above 1.5-fold, highlighting proteomic differences between the two regions. Webgestalt gene ontology analysis of the proteins with $>1.5$-fold change in expression highlighted the top biological processes enriched at a level of $p<0.05$ (Additional file 5: Table S5 and Additional file 6: Table S6). The proteins that were shown to increase in the presubiculum compared to the entorhinal cortex were enriched for biosynthetic and biogenetic processes as well as metabolic changes. However, the proteins that were shown to decrease in the presubiculum compared to the entorhinal cortex were enriched for cell organisation and cell signalling.

Among the proteins identified as altered between the two brain regions, we found a proportion previously reported as AD-associated proteins. These included proteins associated with amyloid processing and fibrillisation, tau accumulation, and inflammation such as SNX6 and RAB21 which were only detected in the entorhinal cortex and S100A8 and OTUB1 were decreased in the presubiculum (14.8-fold and 2-fold respectively). SNX6 negatively regulates BACE1 cleavage of APP [54]. RAB21 overexpression results in greater $A \beta$ production, whereas silencing of this gene reduces the $A \beta$ levels [70]. S100A8 is thought to aggregate itself prior to $A \beta$ plaque formation and treatment of a neuronal cell line with S100A8 leads to increased A $\beta 1-42$ but decreased levels of A $\beta 1-40$ [45]. Furthermore, S100A8 forms a heterodimeric complex with S100A9 molecules which then elicits an inflammatory response. S100A9 is increased in the presubiculum in this data set, whereas S100A8 was decreased $[19,29]$. Therefore we can 


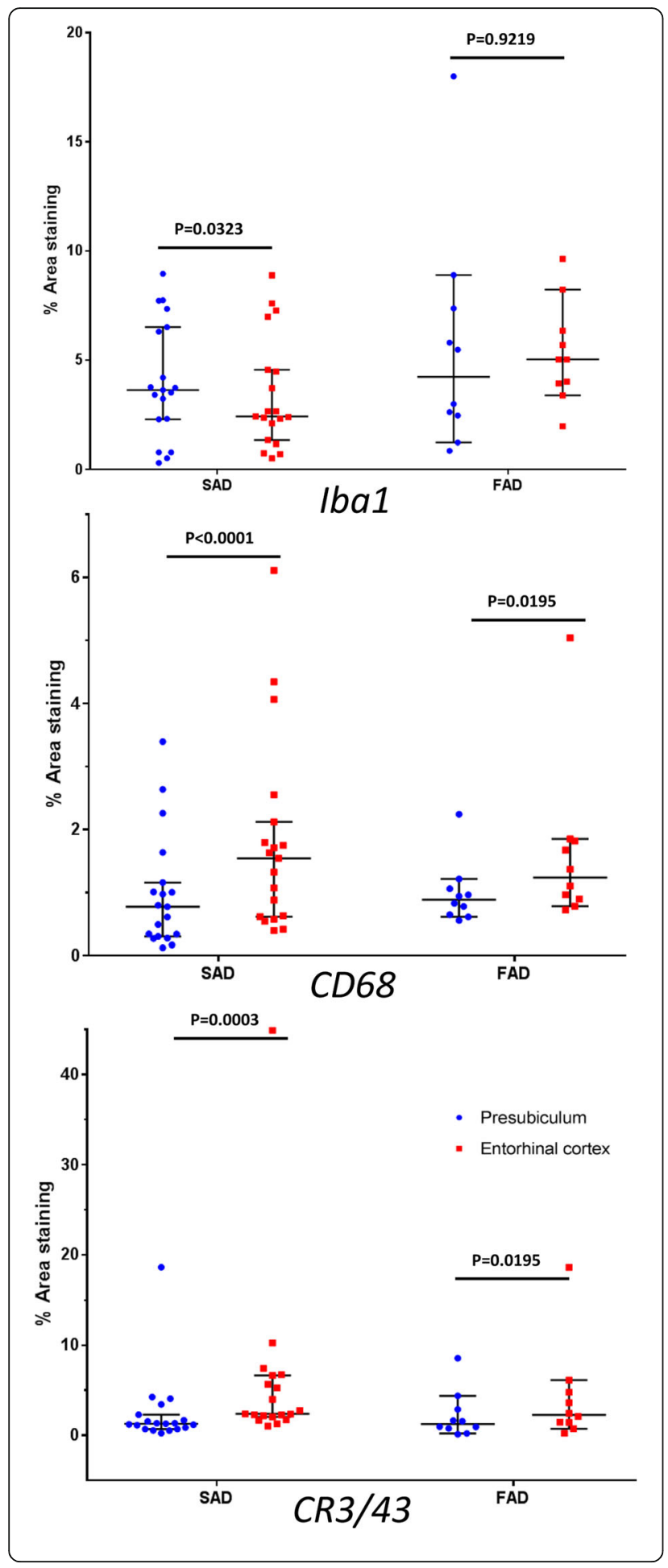

Fig. 4 Quantification of tau immunohistochemistry in the presubiculum and entorhinal cortex. The density of the tau immunohistochemistry observed in the entorhinal cortex and presubiculum was quantitated. The overall density included NFTs and neuropil threads was significantly higher in the entorhinal cortex compared to the presubiculum. The number of NFTs was also significantly higher in the entorhinal cortex compared to the presubiculum. FAD; Familial Alzheimer's disease: SAD; Sporadic Alzheimer's disease. Bars represent medians with 95\% confidence intervals. Wilcoxon paired rank test was performed in each case and $p$ values are shown.

hypothesis that this complex is not active in the presubiculum [36, 37]. OTUB1 (OTU Deubiquitinase, Ubiquitin Aldehyde Binding 1), a tau deubiquitinating enzyme, has been shown to increase AT8 positive tau accumulation and to increase tau-seeded tau aggregation [82].

Inflammatory proteins detected included DOCK2, decreased 9.4 fold in the presubiculum and INPP5D, increased 2.2-fold in the presubiculum. DOCK2 is part of the prostaglandin pathway and has been shown to modulate microglial cytokine secretion and phagocytosis [12]. INPP5D is a negative regulator of the innate immune system. It has been linked to AD in GWAS studies [18, 24, 49]. Additionally, multiple annexins showed protein expression changes between regions. ANXA4 (329.9 fold, pellet), ANXA7 (4.3 fold, pellet), ANXA1 (2 fold, pellet), ANXA6 (1.7 fold, pellet), ANXA5 (1.4 fold, pellet, 1.2 supernatent), ANXA11 (1.4 fold, pellet) and ANXA2 (1.03 fold, pellet) were found to be decreased in the presubiculum. The annexins are a multigene family that are $\mathrm{Ca}^{2+}$ and phospholipid binding proteins. They have a range of roles including involvement in inflammation. Annexin A1 promotes resolution of inflammation by supressing microglial activation and inhibiting secretion of their pro-inflammatory cytokines [59]. Annexin A2 has been shown to modulate pro-inflammtory cytokines and reactive oxygen species [26]. Annexin A5 inhibits phagocytosis and also regulates cytokine secretion and Annexin A6 has a role in $\mathrm{T}$ cell proliferation $[14,62]$.

Immunohistochemical analysis of candidate proteins in AD To validate the proteins of interest detected by $\mathrm{MS}^{\mathrm{e}}$ label free proteomics, immunohistochemical analysis was performed on the hippocampal sections containing the presubiculum and entorhinal cortex. Proteins to validate were chosen based on the proteomic data, published literature and commercially available antibodies previously used with paraffin embedded tissue. To assess the effect on inflammation in the presubiculum one protein that was increased in the presubiculum (DOCK2), one protein that was decreased in the presubiculum (INPP5D). The annexin protein family were also significantly changes between the two brain regions and two annexins (ANXA1 and ANXA2) were investigated using commercially available antibodies. DOCK2, and INPP5D did not show any 


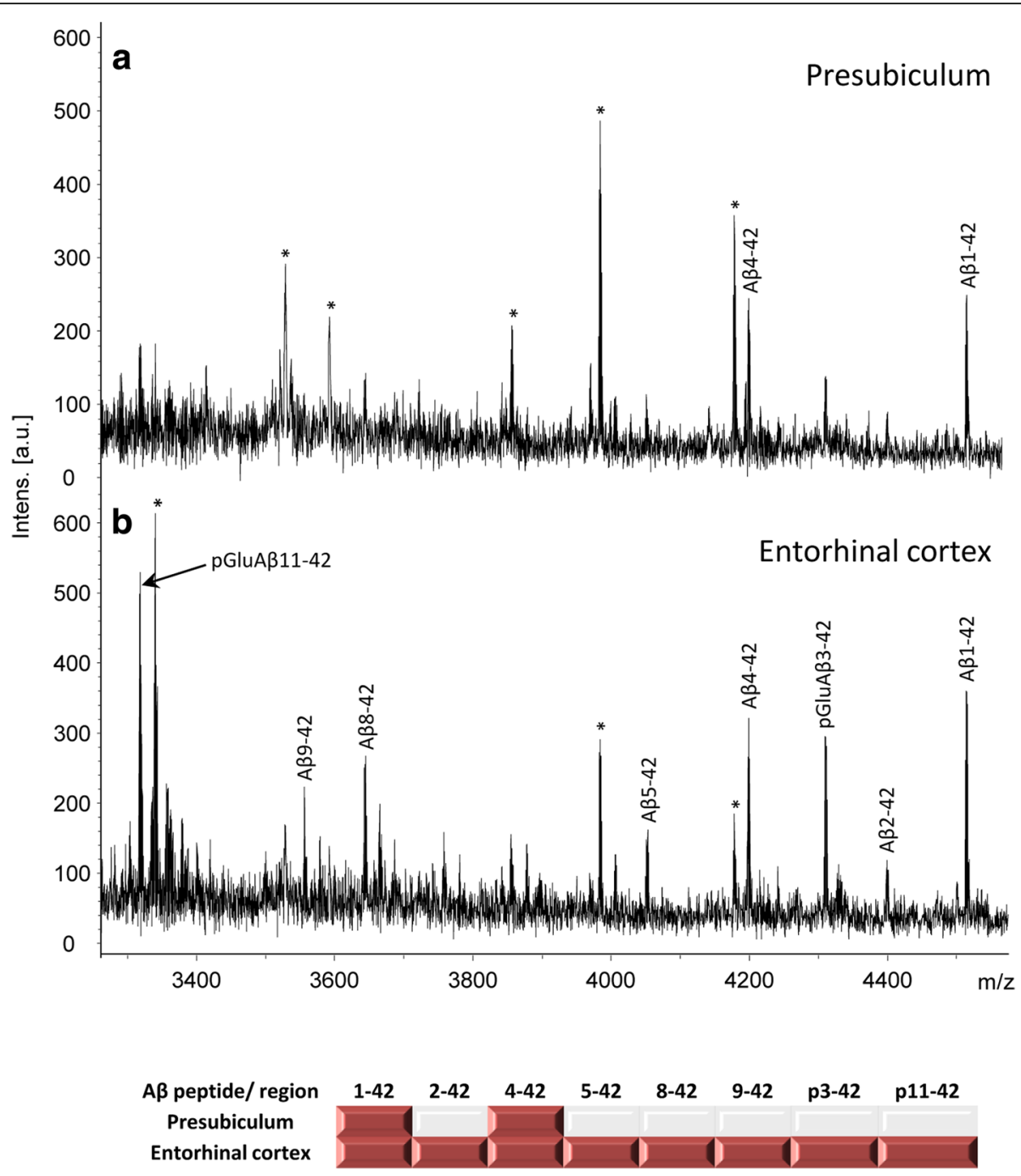

Fig. 5 Mass spectra of the $A \beta$ peptide pattern from the presubiculum and entorhinal cortex. Representative mass spectra from case 3 highlights the differences between the full length $A \beta$ species identified in the presubiculum (a) compared to the truncated and post-translationally modified $A \beta$ species identified in the entorhinal cortex (b).The table shows the $A \beta$ isoforms present in the presubiculum and entorhinal cortex from six Alzheimer's disease cases. * represent unidentified non-A $\beta$ related peaks. A peak was considered as identified if the signal-to-noise was $>2$

positive staining in the presubiculum or the entorhinal cortex. However ANXA1 and ANXA2 antibodies stained astrocytes and astrocytic processes in the entorhinal cortex. However there was no staining in the presubiculum (Fig. 7), validating the proteomic results obtained in the pellet by mass spectrometry.

\section{Discussion}

This study aimed to investigate the pathological features in the morphologically diverse presubiculum and entorhinal cortex in three cerebral amyloidosis. We have shown that, regardless of the amino acid sequence of the three amyloid peptides $A \beta, A B r i$ and $A D a n$ they form similar diffuse, 'lake-like' structures in the presubiculum in $\mathrm{AD}, \mathrm{FBD}$ and FDD respectively. This observation underpins the notion that this morphological phenomenon of the presubiculum is not a unique feature of the $A \beta$ peptide of $A D$, but is also seen in FBD and FDD. The lack of binding to $\beta$-pleated sheet ligands, such as Thioflavin-S, implies that the large diffuse 'lake-like' deposits seen in the presubiculum of the three cerebral amyloid diseases are primarily composed of non-fibrillar peptide aggregates [2, 30, 31, 84]. A recent study on binding of amyloid tracers to $A \beta$ aggregates showed no binding of the PiB PET ligand in the presubiculum of $A D$ patients, also indicating that the $A \beta$ deposits found in the presubiculum are not in amyloid conformation [36].

It has been suggested that diffuse plaques with nonfibrillar $A \beta$ undergo fibrillization and become amyloid/ neuritic plaques [13, 33, 46, 55, 57]. However, the large 


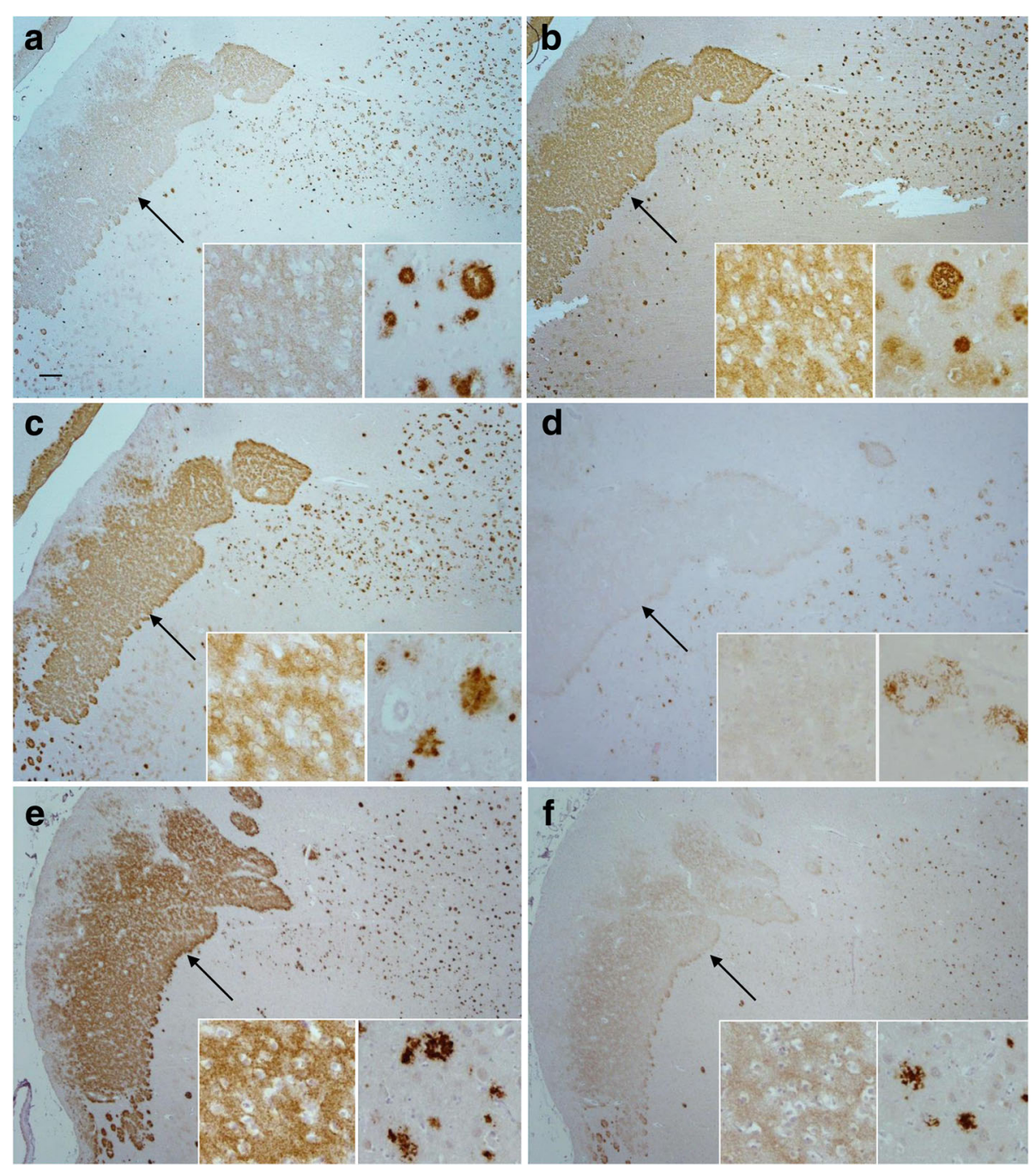

Fig. 6 pGlu-A $A$ immunohistochemistry in the presubiculum and entorhinal cortexlmmunohistochemical analysis of pGlu truncated $A \beta$ species was carried out with four antibodies A $\beta-p E 3$ (a; Synaptic systems 218,311; clone 1-57); A $\beta$-pE3 (b; Synaptic systems 218,011; clone 2-48); A -pE3 (c; Synaptic systems 218,003); Aß-pE11 (d; Synaptic systems 218,811; clone 173D8); Aß4-x (e; [83]; Aß1-5 (f; Synaptic systems 218,231). All antibodies showed a degree of positive staining in both the presubiculum and the entorhinal cortex. Bar in A represents $250 \mu \mathrm{m}$ in a, b, c and d and $20 \mu \mathrm{m}$ in the inserts

diffuse, 'lake-like' A $\beta$ deposits of the presubiculum do not progress into mature amyloid plaques. Considering the phases of $\mathrm{A} \beta$ deposition in $\mathrm{AD}$, diffuse plaques appear in the presubiculum in Thal phase 2 in around one third of the cases to be present in all cases by Thal phase 3 . The morphology of such 'lake-like' deposits remains unaltered during progression of the amyloid pathology from Thal phase 3 to Thal phase 5 indicating that these large $A \beta$ deposits do not fibrillise into amyloid [74].

In this study further biochemical and proteomic analysis was carried out in the AD cases to understand the morphological differences between the presubiculum and the entorhinal cortex. Biochemical analysis was carried out in a limited number of cases, however the results were conclusive for each case and the proteomic investigations were carried out as preliminary investigations to understand difference in molecular pathways between the two brain regions. In this study we identified $A \beta_{1-42}$ and $A \beta_{4-42}$ in the presubiculum and no $A \beta$ peptides terminating at residue 40 with mass spectrometry, whereas plaques isolated from the entorhinal cortex contained a mixture of $A \beta$ peptides of various lengths with pyroglutamate modifications at positions 3 and 11 . The $A \beta$ peptides are generated by proteolytic cleavage of the larger amyloid precursor protein (APP) by $\beta$ - and $\gamma$-secretase [22, 27, 67]. While a single protein BACE1 is responsible for the $\beta$-secretase activity, $\gamma$-secretase is composed of four essential subunits: presenilin 1 (PS1) or presenilin 2 (PS2), together with nicastrin, APH-1 and PEN-2 [53, 76]. The $\gamma$-secretase complex cleaves at multiple sites within the transmembrane domain 


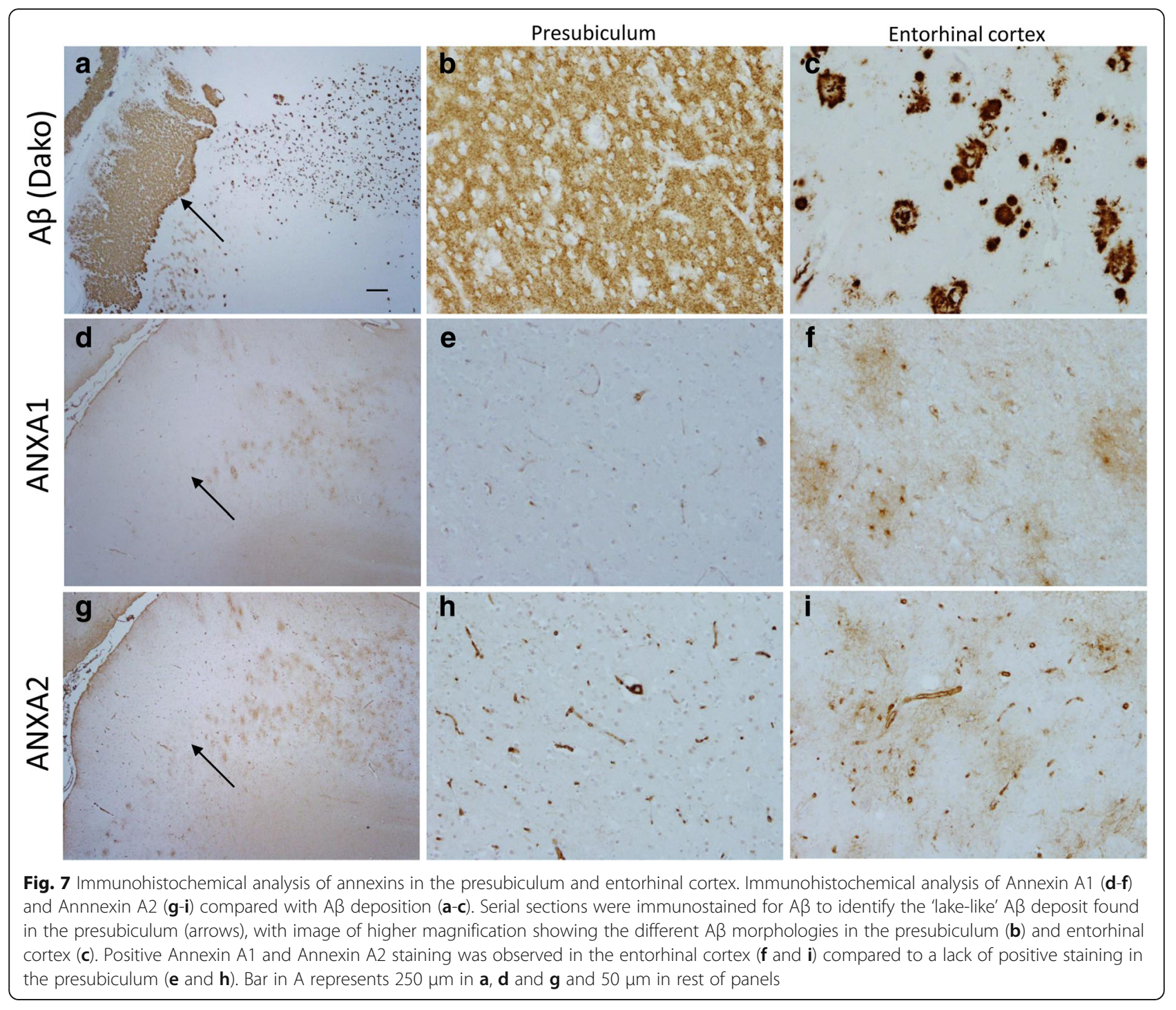

of APP, generating A $\beta$ peptides ranging in length [66]. It is known that the distribution of these species varies among different pathological lesions. Parenchymal deposits consist of $A \beta_{42}$ as the major component, whereas $A \beta$ deposits within vessels are mainly $A \beta_{40}$ [61]. The reasons and relevance of this selectivity remains unclear. The biophysical and biochemical properties of $A \beta$ vary immensely with its length, the longer $A \beta_{42}$ has a much greater tendency to aggregate than the shorter $A \beta_{40}[34,35]$. Furthermore the relative ratio of $A \beta_{40}$ to $A \beta_{42}$ influences the biological effects of the $A \beta$ mixture in vivo and in vitro even when total amounts of $A \beta$ are kept equal [40] suggesting that the ratio of $A \beta_{40} / A \beta_{42}$ is more important than the absolute amounts of $A \beta_{42}$ [72]. The ratio also influences the morphological phenotype of the underlying pathology; by increasing the amount of $A \beta_{42}$ the pathology shifts from predominantly CAA to parenchymal plaques [28]. Post-translational modifications of $A \beta$ result in $N$-terminally truncated $A \beta$ with pyroglutamate modifications at position $3\left(\mathrm{~A} \beta_{\mathrm{N} 3 \mathrm{pE}}\right)$ or 11 $\left(\mathrm{A} \beta_{\mathrm{N} 11 \mathrm{pE}}\right)$. Pyroglutamate modification is associated with enhanced aggregation into oligomers and fibrils. Biochemically, $A \beta_{42}$ is the first $A \beta$ species to accumulate in the human brain $[33,44] . A \beta_{40}$ is detected subsequently, followed by $\mathrm{N}$-terminal truncated and pyroglutamate-modified $A \beta_{\mathrm{N} 3 \mathrm{pE}}$ and/or $\mathrm{A} \beta_{\mathrm{N} 11 \mathrm{pE}}$. These modified forms of $A \beta$ are frequently detected in plaques of all $\mathrm{AD}$ cases $[33,44,60]$. The $\mathrm{A} \beta$ species detected by mass spectrometry in the presubiculum showed no pyroglutamate modifications, suggesting that the $A \beta$ peptides found in the presubiculum are not modified overtime. However, we could detect pyroglutamate modified peptides when using pGlu specific antibodies. This may indicate that relatively small concentrations of these peptides are found in the presubiculum. It is also of note that the FAD cases investigated in this study carried mutations in the APP and PSEN1 genes, both mutations resulting in 
the production of different amounts of the $A \beta$ variants. Yet all cases regardless of mutation status have the same characteristic morphology, and mass spectrometry profile of $\mathrm{A} \beta$ in the presubiculum. $\mathrm{N}$-terminally truncated and pyroglutamate-modified $\mathrm{A} \beta$ peptides have previously been shown in dense amyloid plaques, so lower quantities in the presubiculum may suggest that these modifications of $A \beta$ are required for amyloid fibrils to form.

Although the contribution of the canonical $\alpha-, \beta$ - and $\gamma$-secretases to APP processing have been studied in depth, the proteolytic cleavage of APP may be more complex. An increasing number of additional secretases have been identified that also proteolytically process APP [3]. However, further investigations on the underlying secretases involved in the processing and cleavage of $\mathrm{A} \beta$ are needed to determine whether other secretases or related proteins are found in the presubiculum compared to the entorhinal cortex $[11,71]$. This though would not account for the large diffuse protein deposit composed of ABri or ADan in FBD and FDD as these proteins are not cleaved by secretases [41]. A link between BRI2 and APP has been demonstrated; where BRI2 has been shown to specifically interact with APP. As a result of this interaction BRI2 masks the cleavage sites of $\beta$ - and $\alpha$-secretase on APP and the $\gamma$-secretase docking site on the APP C-terminal fragment C99. Thus, BRI2 modulates APP processing by inhibiting $A \beta$ formation and its deposition properties $[20,47,48]$. FBD and FDD are due to mutations in the BRI2 gene, and both mutations cause the precursor protein to be extended and through a furin-like processing two 34 amino acid peptides are generated (ABri and ADan respectively). ABri molecules have a higher tendency to form ordered oligomeric assembles than $A \beta_{42}$ [63]. Therefore the morphological phenomenon observed in the presubiculum of three neurodegenerative diseases caused by the deposition of three different proteins would suggest that the observed phenomenon would likely be due to local tissue factors in the presubiculum rather than the processing of the different proteins.

It has previously been shown that despite the accumulation of $A \beta$ in the presubiculum, neurofibrillary degeneration is minimal $[2,7,21,37]$, whereas the neighbouring entorhinal cortex and subiculum had considerable numbers of NFTs [7]. We have quantitated these findings in this study and found significantly more NFTs in the entorhinal cortex compared to the minimal number of NFTs found in the presubiculum. Previous studies have demonstrated that there is no neuronal loss in the presubiculum in AD compared to normal controls [21], showing that although neurons are present significantly fewer NFTs form in the presubiculum.

In the healthy brain microglia actively support neurons through the release of nerve growth factors $[15,50,78]$ and have been shown to carry out many activities including synaptic pruning $[1,65]$. The classification of microglia into pro-inflammatory or anti-inflammatory forms is based on the phenotypes of peripheral macrophages $[38,51,58]$. Pro-inflammatory are characterised by increased expression of pro-inflammatory mediators and cytokines [58] that retract their processes and adopt an amoeboid morphology often migrating closer to the site of injury [16]. Anti-inflammatory microglia are characterised by increased cytokine expression and associated with increased ramification of processes [58]. In the $\mathrm{AD}$ brain activated pro-inflammatory microglia are typically located in brain regions affected by disease and surround $A \beta$ amyloid plaques [32]. However, the involvement of microglia in the neuroinflammatory processes is now understood to be a complex continuum rather than the originally proposed pro-inflammatory and anti-inflammatory polarised states [86]. In this study we showed a significant increase in the presence of CD68 and CR3-43 positive microglia in the entorhinal cortex compared to the presubiculum. Even though the number of microglia within the presubiculum and entorhinal cortex, as demonstrated by Iba1 staining, were not significantly different. Microglia have been proposed to assist in the clearance of $A \beta$ from the brain [73], however this clearance by microglia is reduced in $\mathrm{AD}$ [43]. The lack of reactive microglia in the presubiculum would suggest that these cells are not engaged in pre-amyloid removal and are able to undertake their non-inflammatory functions specifically relating to maintenance of the central nervous system $[1,65]$. Recently, Sosna et al. demonstrated that when microglia are ablated via CSF1R (Colony-stimulating factor 1 receptor) inhibition, there is a significant reduction of neuritic plaque formation and pre-fibrillar amyloid present in 5xFAD Tg mice [68], suggesting that microglia are instrumental in the formation of neuritic plaques.

We investigated alterations in protein expression in the presubiculum compared to the entorhinal cortex to assess whether a local difference in protein expression could contribute to the morphological and biochemical differences in the two brain regions. We demonstrated that 429 proteins had an increased expression in the presubiculum compared to the entorhinal cortex in both soluble and insoluble fractions whereas 850 proteins were shown to be decreased in the presubiculum. The proteins identified spanned many different biological processes from phospholipase activity and enzyme inhibitor activity being increased to neurotransmitter transport and synaptic transmission being decreased. We selected proteins for further validation based on the most prominent biological functions represented, the greatest fold change and the availability of commercially available antibodies. From the proteins selected, ANXA1 and ANXA2 both differed in staining pattern showing positive staining in the entorhinal cortex and was negative in the presubiculum. Further 
investigation into the annexin pathways and inflammatory mechanisms may identify why this region appears to be protected from neurodegeneration compared to its neighbouring regions.

We found that the 'lake-like' pre-amyloid deposits found in the presubiculum are not a unique feature in AD but is also found in other cerebral amyloidosis. Significant quantitative differences were found in the amount of tau, number of NFTs and the amount of microglial activation in the presubiculum compared to the entorhinal cortex. Proteomic differences were found in the $A \beta$ species and the whole proteome between the two brain regions. In summary, understanding why the presubiculum has a different morphological appearance, biochemical and proteomic makeup compared to surrounding brain regions severely affected by neurodegeneration could lead us to understanding protective mechanisms in neurodegenerative diseases.

\section{Additional files}

Additional file 1: Table S1. Proteins identified in supernatant with increased expression in the presubiculum compared to the entorhinal cortex in Alzheimer's disease post-mortem brain tissue. (DOCX $24 \mathrm{~kb}$ )

Additional file 2: Table S2. Proteins identified in the pellet with increased expression in the presubiculum compared to the entorhinal cortex in Alzheimer's disease post-mortem brain tissue. (DOCX 38 kb)

Additional file 3: Table S3. Proteins identified in supernatant with decreased expression in the presubiculum compared to the entorhinal cortex in Alzheimer's disease post-mortem brain tissue. (DOCX 24 kb)

Additional file 4: Table S4. Proteins identified in the pellet with decreased expression in the presubiculum compared to the entorhinal cortex in Alzheimer's disease post-mortem brain tissue. (DOCX 86 kb)

Additional file 5: Table S5. Webgestalt GO ontology terms showing increased expression in the presubiculum compared to the entorhinal cortex in Alzheimer's disease post-mortem brain tissue. (DOCX 18 kb)

Additional file 6: Table S6. Webgestalt GO ontology terms showing decreased expression in the presubiculum compared to the entorhinal cortex in Alzheimer's disease post-mortem brain tissue. (DOCX 18 kb)

\section{Acknowledgements and funding}

Tammaryn Lashley is supported by an Alzheimer's Research UK senior fellowship. Christina Murray was supported by an Alzheimer's Research UK PhD Studentship and is now supported by the UK Dementia Research Institute at UCL. Priya Gami-Patel and Henrik Zetterberg are supported by the Leonard Wolfson Centre for Experimental Neurology. Tamas Revesz is supported by a grant from CBD Solutions. The Queen Square Brain Bank is supported by the Reta Lila Weston Institute for Neurological Studies, the Progressive Supranuclear Palsy Association and the Medical Research Council. Janice Holton is supported by the Multiple System Atrophy Trust; the Multiple System Atrophy Coalition; Fund Sophia, managed by the King Baudouin Foundation; Alzheimer's Research UK and CBD Solutions. This research was partly supported by the UK Dementia Research Institute at UCL and the National Institute for Health Research (NIHR) Queen Square Biomedical Research Unit in Dementia based at University College London Hospitals $(\mathrm{UCLH})$, University College London (UCL). The views expressed are those of the author(s) and not necessarily those of the NHS, the NIHR or the Department of Health. The Clinical Neurochemistry Laboratory is supported by the Swedish and European Research Councils, the Knut and Alice Wallenberg Foundation, the Swedish Brain Foundation, the Torsten Söderberg Foundation and Alzheimerfonden. FDD samples were provided by Neuropathology Department, Århus Kommunehospital, Århus, Denmark and FBD samples provided by Department of Neuropathology, UCL Institute of Neurology. We would like to thank the Peto Foundation for their kind donations to the UCL mass spectrometry research group.

\section{Authors' contributions}

TL and TR drafted the study design, CM and PGP undertook the wet lab work and analysis. JG and OW provided the antibodies. EG, GB, EP, WH, KB, $\mathrm{KM}$ and $\mathrm{HZ}$ provided support and expertise for the mass spectrometry. All authors read and contributed to the final manuscript.

\section{Ethics approval and consent to participate}

Ethical approval was obtained for the use of post-mortem human brain tissue from the Local Research Ethics Committee of the National Hospital for Neurology and Neurosurgery.

\section{Publisher's Note}

Springer Nature remains neutral with regard to jurisdictional claims in published maps and institutional affiliations.

\section{Author details}

${ }^{1}$ The Queen Square Brain Bank for Neurological Disorders, Department of Molecular Neuroscience, UCL Institute of Neurology, London WC1N 3BG, UK. ${ }^{2}$ Institute of Neuroscience and Physiology, Department of Psychiatry and Neurochemistry, The Sahlgrenska Academy at the University of Gothenburg, Mölndal, Sweden. ${ }^{3}$ Clinical Neurochemistry Laboratory, Sahlgrenska University Hospital, Mölndal, Sweden. ${ }^{4}$ Department of Psychiatry and Psychotherapy, University Medical Center (UMG), Georg-August-University, Goettingen, Germany. ${ }^{5}$ Centre for Translational Omics, Great Ormond Street Institute of Child health, UCL, London, UK. ${ }^{6}$ New York University, New York, NY, USA.

${ }^{7}$ Dementia Research Institute, UCL, London, UK.

Received: 1 June 2018 Accepted: 29 June 2018

Published online: 20 July 2018

\section{References}

1. Aguzzi A, Barres BA, Bennett ML (2013) Microglia: scapegoat, saboteur, or something else? Science 339(6116):156-161. https://doi.org/10.1126/ science.1227901

2. Akiyama H, Tago H, Itagaki S, McGeer PL (1990) Occurrence of diffuse amyloid deposits in the presubicular parvopyramidal layer in Alzheimer's disease. Acta Neuropathol 79(5):537-544. https://doi.org/10.1007/BF00296114

3. Andrew RJ, Kellett KAB, Thinakaran G, Hooper NM (2016) A Greek tragedy: the growing complexity of Alzheimer amyloid precursor protein proteolysis. J Biol Chem 291(37):19235-19244. https://doi.org/10.1074/jbc.R116.746032

4. Augustinack JC, Helmer K, Huber KE, Kakunoori S, Zöllei L, Fischl B (2010) Direct visualization of the perforant pathway in the human brain with ex vivo diffusion tensor imaging. Front Hum Neurosci 4(May):42. https:// doi.org/10.3389/fnhum.2010.00042

5. Bland J, Regression Analysis AD (1986) Lancet:908-909

6. Bliss E, Heywood WE, Benatti M, Sebire NJ, Mills K (2016) An optimised method for the proteomic profiling of full thickness human skin. Biol Proced Biological Procedures Online 18(1):1-7. https://doi.org/10.1186/ s12575-016-0045-y

7. Bobinski M, Wegiel J, Wisniewski HM, Tarnawski M, Reisberg B, Mlodzik B et al (1995) Atrophy of hippocampal formation subdivisions correlates with stage and duration of Alzheimer disease. Dementia 6(4):205-210

8. Boche D, Perry VH, Nicoll JA (2013) Review: activation patterns of microglia and their identification in the human brain. Neuropathol Appl Neurobiol 39(1):3-18. https://doi.org/10.1111/nan.12011

9. Braak H, Braak E (1991) Neuropathological stageing of Alzheimer-related changes. Acta Neuropathol 82:239-259. https://doi.org/10.1007/BF00308809

10. Caballero-Bleda M, Witter MP (1994) Projections from the presubiculum and the parasubiculum to morphologically characterized entorhinalhippocampal projection neurons in the rat. Exp Brain Res 101(1):93-108. https://doi.org/10.1007/BF00243220

11. Chávez-Gutiérrez L, Bammens L, Benilova I, Vandersteen A, Benurwar M, Borgers M et al (2012) The mechanism of $\gamma$-secretase dysfunction in familial Alzheimer disease. EMBO J 31(10):2261-2274. https://doi.org/10.1038/emboj. 2012.79

12. Cimino PJ, Sokal I, Leverenz J, Fukui Y, Montine TJ (2009 Oct) DOCK2 is a microglial specific regulator of central nervous system innate immunity 
found in normal and Alzheimer's disease brain. Am J Pathol 175(4):16221630. https://doi.org/10.2353/ajpath.2009.090443

13. Cork L, Masters C, Beyreuther K, Price D (1990) Development of senile plaques. Relationships of neuronal abnormalities and amyloid deposits. Am J Pathol 137(6):1383-1392

14. Cornely R, Pollock AH, Rentero C, Norris SE, Alvarez-Guaita A, Grewal T et al (2016) Annexin A6 regulates interleukin-2-mediated T-cell proliferation. Immunol Cell Biol 94(6):543-553. https://doi.org/10.1038/icb.2016.15

15. Coull J a M, Beggs S, Boudreau D, Boivin D, Tsuda M, Inoue K et al (2005) BDNF from microglia causes the shift in neuronal anion gradient underlying neuropathic pain. Nature 438(7070):1017-1021. https://doi.org/10.1038/ nature 04223

16. Davalos D, Grutzendler J, Yang G, Kim JV, Zuo Y, Jung S et al (2005) ATP mediates rapid microglial response to local brain injury in vivo. Nat Neurosci 8(6):752-758. https://doi.org/10.1038/nn1472

17. Drexel M, Kirchmair E, Sperk G (2013) Changes in the expression of GABAA receptor subunit mRNAs in parahippocampal areas after kainic acid induced seizures. Front Neural Circuits 7:142. https://doi.org/10.3389/fncir.2013.00142

18. Efthymiou AG, Goate AM (2017) Late onset Alzheimer's disease genetics implicates microglial pathways in disease risk. Mol Neurodegener 12. https://doi.org/10.1186/s13024-017-0184-x

19. Eue I, König S, Pior J, Sorg C (2002) S100A8, S100A9 and the S100A8/A9 heterodimer complex specifically bind to human endothelial cells: identification and characterization of ligands for the myeloid-related proteins S100A9 and S100A8/A9 on human dermal microvascular endothelial cell line-1 c. Int Immunol 14(3):287-297. https://doi.org/10.1093/intimm/14.3.287

20. Fotinopoulou A, Tsachaki M, Vlavaki M, Poulopoulos A, Rostagno A, Frangione $B$ et al (2005) BRI2 interacts with amyloid precursor protein (APP) and regulates amyloid $\beta(A \beta)$ production. J Biol Chem 280(35):30768-30772. https://doi.org/10.1074/jbc.C500231200

21. Fukutani Y, Cairns N, Rossor M, Isaki K, Lantos P (1997) Cerebellar pathology in sporadic and familial Alzheimer's disease: a morphometric investigation. 149:177-184 Available from: https://onlinelibrary.wiley.com/doi/abs/10.1111/ j.1750-3639.1997.tb01009.x.

22. Ghiso J, Frangione B (2002) Amyloidosis and Alzheimer's disease. Adv Drug Deliv Rev 54(12):1539-1551. https://doi.org/10.1016/S0169-409X(02)00149-7

23. Ghiso J, Rostagno A, Tomidokoro Y, Lashley T, Bojsen-Møller M, Braendgaard $\mathrm{H}$ et al (2006) Genetic alterations of the BRI2 gene: familial British and Danish dementias. Brain Pathol 16(1):71-79 Available from: http://www.ncbi. nlm.nih.gov/pubmed/16612984

24. Gjoneska E, Pfenning AR, Mathys H, Quon G, Kundaje A, Tsai L-H et al (2015 Feb) Conserved epigenomic signals in mice and humans reveal immune basis of Alzheimer/'s disease. Nature 518(7539):365-369. https://doi.org/10. 1038/nature14252

25. Gundersen H, Bendtsen T, Korbo L, Marcussen N, Moller A, Nielsen K et al (1988) Some new, simple and efficient stereological methods and their use in pathological research and diagnosis. APMIS 96(5):379-394

26. He S, Li X, Li R, Fang L, Sun L, Wang Y et al (2016) Annexin A2 modulates ROS and Impacts inflammatory response via IL-17 signaling in Polymicrobial Sepsis mice. PLoS Pathog 12(7):1-23. https://doi.org/10.1371/journal.ppat.1005743

27. Hébert SS, Serneels L, Dejaegere T, Horré K, Dabrowski M, Baert V et a (2004) Coordinated and widespread expression of $\gamma$-secretase in vivo: evidence for size and molecular heterogeneity. Neurobiol Dis 17(2):260-272. https://doi.org/10.1016/j.nbd.2004.08.002

28. Herzig MC, Winkler DT, Burgermeister P, Pfeifer M, Kohler E, Schmidt SD et al (2004) Abeta is targeted to the vasculature in a mouse model of hereditary cerebral hemorrhage with amyloidosis. Nat Neurosci 7(9):954960. https://doi.org/10.1038/nn1302

29. Hessian PA, Fisher $L$ (2001) The heterodimeric complex of MRP-8 (S100A8) and MRP-14 (S100A9) antibody recognition, epitope definition and the implications for structure. Eur J Biochem 268(2):353-363. https://doi.org/10 1046/j.1432-1327.2001.01894.x

30. Holton JL, Ghiso J, Lashley T, Rostagno A, Guerin CJ, Gibb G, et al (2001) Regional distribution of amyloid-Bri deposition and its association with neurofibrillary degeneration in familial British dementia. Am J Pathol Am Soc Invest Pathol 158(2):515-526. Available from: https://www.ncbi.nlm.nih gov/pubmed/11159188.

31. Holton JL, Lashley T, Ghiso J, Braendgaard H, Vidal R, Guerin CJ et al (2002) Familial Danish dementia: a novel form of cerebral amyloidosis associated with deposition of both amyloid-Dan and amyloid-beta. J Neuropathol Exp Neurol 61(3):254-267
32. Itagaki S, McGeer P, Akiyama H, Zhu S, Selkoe D (1989) Relationship of microglia and astrocytes to amyloid deposits of Alzheimer disease. J Neuroimmunol 24(3):173-182

33. Iwatsubo T, Saido TC, Mann DM, Lee VM, Trojanowski JQ (1996) Full-length amyloid-beta (1-42(43)) and amino-terminally modified and truncated amyloid-beta 42(43) deposit in diffuse plaques. Am. J Pathol 149(6):1823-1830. https://doi.org/10.1002/ejoc.201001502

34. Jarrett J, Berger E, Lansbury P (1993) The carboxy terminus of the beta amyloid protein is critical for the seeding of amyloid formation: implications for the pathogenesis of Alzheimer's disease. Biochemistry 32(18):4693-4697

35. Jarrett JT, Lansburry PT (1993) Seeding "one dimensional cristallization" of amyloid: a pathogenic mechanism in Alzheimer's disease and scrapie? Cell 73:1055-1058. https://doi.org/10.1016/0092-8674(93)90635-4

36. Ji B, Chen CJ, Bando K, Ashino H, Shiraishi H, Sano H et al (2015) Distinct binding of amyloid imaging ligands to unique amyloid- $\beta$ deposited in the presubiculum of Alzheimer's disease. J Neurochem 135(5):859-866. https://doi.org/10.1111/jnc.13293

37. Kalus P, Braak H, Braak E, Bohl J (1989) The presubicular region in Alzheimer's disease: topography of amyloid deposits and neurofibrillary changes. Brain Res 494(1):198-203. https://doi.org/10.1016/0006-8993(89)90164-9

38. Kettenmann H, Hanisch U-K, Noda M, Verkhratsky A (2011) Physiology of microglia. Physiol Rev 91 (2):461-553. https://doi.org/10.1152/physrev.00011.2010

39. Korzhevskii DE, Kirik OV (2016) Brain microglia and microglial markers. Neurosci Behav Physiol 46(3):284-290. https://doi.org/10.1007/s1 1055-016-0231-z

40. Kuperstein I, Broersen K, Benilova I, Rozenski J, Jonckheere W, Debulpaep M et al (2010) Neurotoxicity of Alzheimer's disease A $\beta$ peptides is induced by small changes in the Aß42 to A 340 ratio. EMBO J 29(19):3408-3420. https://doi.org/10.1038/emboj.2010.211

41. Lashley T, Revesz T, Plant G, Bandopadhyay R, Lees A, Frangione B et al (2008) Expression of BRI2 mRNA and protein in normal human brain and familial British dementia:its relevance to the pathogenesis of disease. Neuropathol Appl Neurobiol 34(5):492-505. https://doi.org/10.1111/j.13652990.2008.00935.x.Expression

42. Lashley T, Rohrer JD, Bandopadhyay R, Fry C, Ahmed Z, Isaacs AM et al (2011 Sep) A comparative clinical, pathological, biochemical and genetic study of fused in sarcoma proteinopathies. Brain 134(Pt 9):2548-2564. https://doi.org/10.1093/brain/awr160

43. Lee CYD, Landreth GE (2010) The role of microglia in amyloid clearance from the AD brain. J Neural Transm 117(8):949-960. https://doi.org/10.1007/ s00702-010-0433-4

44. Lemere CA, Blusztajn JK, Yamaguchi H, Wisniewski TM, Saido TC, Selkoe DJ (1996) Sequence of deposition of heterogeneous amyloid beta-peptides and APO E in Down syndrome: implications for initial events in amyloid plaque formation. Neurobiol Dis 3(1):16-32. https://doi.org/10.1006/nbdi.1996.0003

45. Lodeiro M, Puerta E, Ismail M-A-M, Rodriguez-Rodriguez P, Rönnbäck A, Codita A et al (2017) Aggregation of the Inflammatory S100A8 Precedes A $\beta$ Plaque Formation in Transgenic APP Mice: Positive Feedback for S100A8 and AB Productions. J Gerontol A Biol Sci Med Sci 72(3):319-328. https://doi.org/10.1093/gerona/glw073

46. Mann D, JOnes D, South P, Snowden J, Neary D (1992) Deposition of amyloid beta protein in non-Alzheimer dementias: evidence for a neuronal origin of parenchymal deposits of beta protein in neurodegenerative disease. Acta Neruopathol 83(4):415-419

47. Matsuda S, Giliberto L, Matsuda Y, Davies P, McGowan E, Pickford F et al (2005) The familial dementia BRI2 gene binds the alzheimer gene amyloid- $\beta$ precursor protein and inhibits amyloid- $\beta$ production. J Biol Chem 280(32): 28912-28916. https://doi.org/10.1074/jbc.C500217200

48. Matsuda S, Giliberto L, Matsuda Y, McGowan EM, D'Adamio L (2008) BRI2 inhibits amyloid -peptide precursor protein processing by interfering with the docking of secretases to the substrate. J Neurosci 28(35):8668-8676. https://doi.org/10.1523/JNEUROSCI.2094-08.2008

49. McKeever PM, Kim T, Hesketh AR, MacNair L, Miletic D, Favrin G et al (2017) Cholinergic neuron gene expression differences captured by translational profiling in a mouse model of Alzheimer's disease. Neurobiol. Aging 57(Supplement C):104-119. https://doi.org/10.1016/..neurobiolaging.2017.05.014

50. Miao J, Ding M, Zhang A, Xiao Z, Qi W, Luo N et al (2012) Pleiotrophin promotes microglia proliferation and secretion of neurotrophic factors by activating extracellular signal-regulated kinase 1/2 pathway. Neurosci. Res. Elsevier Ireland Itd and Japan neuroscience Society 74(3-4):269-276. https://doi.org/10.1016/j.neures.2012.09.001 
51. Mills C (2012) M1 and M2 macrophages: oracles of health and disease. Crit Rev Immunol 32(6):463-488

52. Montine T, Phelps C, Beach T, Bigio E, Cairns N, Dickson D et al (2012) National Institute on Aging-Alzheimer's association guidelines for the neuropathologic assessment of Alzheimer's disease: a practical approach. Acta Neuropathol 123(1):1-11. https://doi.org/10.1007/s00401-011-0910-3.National

53. Niimura M, Isoo N, Takasugi N, Tsuruoka M, Ui-Tei K, Saigo K et al (2005) Aph-1 contributes to the stabilization and trafficking of the ??-secretase complex through mechanisms involving intermolecular and intramolecular interactions. J Biol Chem 280(13):12967-12975. https://doi.org/10.1074/jbc.M409829200

54. Okada H, Zhang W, Peterhoff C, Hwang JC, Nixon RA, Ryu SH et al (2010) Proteomic identification of sorting nexin 6 as a negative regulator of BACE1-mediated APP processing. FASEB J 24(8):2783-2794. https://doi.org/ 10.1096/fj.09-146357

55. Pappolla MA, Omar RA, Vinters HV (1991) Image analysis microspectroscopy shows that neurons participate in the genesis of a subset of early primitive (diffuse) senile plaques. AmJPathol 139(0002-9440):599-607

56. Portelius E, Lashley T, Westerlund A, Persson R, Fox NC, Blennow K et al (2015) Brain amyloid-Beta fragment signatures in pathological ageing and Alzheimer's disease by hybrid immunoprecipitation mass spectrometry. Neurodegener Dis 15(1):50-57. https://doi.org/10.1159/000369465

57. Probst A, Langui D, Ulrich J (1991) Alzheimer's disease: a description of the structural lesions. Brain Pathol 1(4):229-239. https://doi.org/10.1111/j.17503639.1991.tb00666.x

58. Ransohoff RM, Perry VH (2009) Microglial physiology: unique stimuli, specialized responses. Annu Rev Immunol 27(1):119-145. https://doi.org/10. 1146/annurev.immunol.021908.132528

59. Ries M, Loiola R, Shah UN, Gentleman SM, Solito E, Sastre M (2016) The antiinflammatory Annexin A1 induces the clearance and degradation of the amyloidB peptide. J Neuroinflammation 13(1). https://doi.org/10.1186/s12974-016-0692-6

60. Rijal Upadhaya A, Kosterin I, Kumar S, Von Arnim CAF, Yamaguchi H, Fändrich $M$ et al (2014) Biochemical stages of amyloid- $\beta$ peptide aggregation and accumulation in the human brain and their association with symptomatic and pathologically preclinical Alzheimer's disease. Brain 137(3):887-903. https://doi.org/10.1093/brain/awt362

61. Roher a E, Palmer KC, Yurewicz EC, Ball MJ, Greenberg BD. Morphological and biochemical analyses of amyloid plaque core proteins purified from Alzheimer disease brain tissue. J Neurochem 1993;61(5):1916-26. Available from: http://www.ncbi.nlm.nih.gov/pubmed/8229002

62. Rosenbaum S, Kreft S, Etich J, Frie C, Stermann J, Grskovic I et al (2011) Identification of novel binding partners (annexins) for the cell death signal phosphatidylserine and definition of their recognition motif. J Biol Chem 286(7):5708-5716. https://doi.org/10.1074/jbc.M110.193086

63. Rostagno A, Tomidokoro Y, Lashley T, Ng D, Plant G, Holton J et al (2005) Chromosome 13 dementias. Cell Mol Life Sci 62(16):1814-1825. https://doi. org/10.1007/s00018-005-5092-5

64. Russo C, Violani E, Salis S, Venezia V, Dolcini V, Damonte G et al (2002) Pyroglutamate-modified amyloid $\beta$-peptides - A $\beta N 3(\mathrm{pE})$ - strongly affect cultured neuron and astrocyte survival. J Neurochem 82(6):1480-1489. https://doi.org/10.1046/j.1471-4159.2002.01107.x

65. Schafer D, Stevens B (2013) Phagocytic glial cells: sculpting synaptic circuits in the developing nervous system. Curr Opin Neurobiol 23(6):1034-1040. https://doi.org/10.1016/j.immuni.2010.12.017.Two-stage

66. Selkoe DJ, Wolfe MS (2007) Presenilin: running with scissors in the membrane. Cell 131(2):215-221. https://doi.org/10.1016/j.cell.2007.10.012

67. Shirotani K, Edbauer D, Prokop S, Haass C, Steiner H (2004) Identification of distinct $\gamma$-secretase complexes with different $\mathrm{APH}-1$ variants. J Biol Chem 279(40):41340-41345. https://doi.org/10.1074/jbc.M405768200

68. Sosna J, Philipp S, Albay RI, Reyes-Ruiz JM, Baglietto-Vargas D, LaFerla FM, et al. Early long-term administration of the CSF1R inhibitor PLX3397 ablates microglia and reduces accumulation of intraneuronal amyloid, neuritic plaque deposition and pre-fibrillar oligomers in 5XFAD mouse model of Alzheimer's disease. Mol. Neurodegener. Mol Neurodegener; 2018;13(1):1-11. doi:https://doi.org/10.1186/s13024-018-0244-X

69. Streit WJ, Braak H, Xue Q-S, Bechmann I (2009) Dystrophic (senescent) rather than activated microglial cells are associated with tau pathology and likely precede neurodegeneration in Alzheimer's disease. Acta Neuropathol 118(4):475-485. https://doi.org/10.1007/s00401-009-0556-6

70. Sun Z, Xie Y, Chen Y, Yang Q, Quan Z, Dai R et al (2017) Rab21, a novel PS1 interactor, regulates $\gamma$-secretase activity via PS1 subcellular distribution. Mol Neurobiol:1-15. https://doi.org/10.1007/s12035-017-0606-3
71. Szaruga M, Veugelen S, Benurwar M, Lismont S, Sepulveda-Falla D, Lleo A, et al. Qualitative changes in human $\gamma$-secretase underlie familial Alzheimer's disease. J. Exp. Med. 2015;(Icd):jem.20150892-. doi:https://doi.org/10.1084/ jem.20150892

72. Tanzi RE, Bertram L (2005) Twenty years of the Alzheimer's disease amyloid hypothesis: a genetic perspective. Cell 120(4):545-555. https://doi.org/10. 1016/j.cell.2005.02.008

73. Tarasoff-conway JM, Carare RO, Osorio RS, Glodzik L, Fieremans E, Axel L et al (2015) Clearance systems in the brain-implications for Alzheimer disease. Nat Rev Neurol 11(8):457-470. https://doi.org/10.1038/nrneurol. 2015.119.Clearance

74. Thal DR, Rüb U, Orantes M, Braak H (2002) Phases of A $A$-deposition in the human brain and its relevance for the development of AD. Neurology 58(12):1791-1800. https://doi.org/10.1212/WNL.58.12.1791

75. Thal DR, Rüb U, Schultz C, Sassin I, Ghebremedhin E, Del Tredici K et al (2000 Aug) Sequence of Abeta -protein deposition in the human medial temporal lobe. J Neuropathol Exp Neurol 59(8):733-748. https://doi.org/10. 1093/jnen/59.8.733

76. Thinakaran G, Koo EH (2008) Amyloid precursor protein trafficking, processing, and function. J Biol Chem 283(44):29615-29619. https://doi.org/10.1074/jbc. R800019200

77. Tomidokoro Y, Lashley T, Rostagno A, Neubert TA, Bojsen-Møller M, Braendgaard $\mathrm{H}$ et al (2005) Familial Danish dementia - co-existence of Danish and Alzheimer amyloid subunits (ADan and a beta) in the absence of compact plaques. J Biol Chem 280(44):36883-36894 Available from: https://www.ncbi.nlm.nih.gov/pubmed/16091362

78. Ueno M, Fujita Y, Tanaka T, Nakamura Y, Kikuta J, Ishii M et al (2013) Layer V cortical neurons require microglial support for survival during postnatal development. Nat Neurosci Nature Publishing Group 16(5):543-551. https://doi.org/10.1038/nn.3358

79. van Strien NM, Cappaert NLM, Witter MP (2009) The anatomy of memory: an interactive overview of the parahippocampal-hippocampal network. Nat Rev Neurosci 10(4):272-282. https://doi.org/10.1038/nrn2614

80. Vidal R, Frangione B, Rostagno A, Mead S, Révész T, Plant G et al (1999) A stop-codon mutation in the BRI gene associated with familial British dementia. Nature 399(6738):776-781. https://doi.org/10.1038/21637

81. Vidal R, Revesz T, Rostagno A, Kim E, Holton JL, Bek T et al (2000) A decamer duplication in the $3^{\prime}$ region of the BRI gene originates an amyloid peptide that is associated with dementia in a Danish kindred. Proc Natl Acad Sci U S A 97(9):4920-4925. https://doi.org/10.1073/pnas.080076097

82. Wang P, Joberty G, Buist A, Vanoosthuyse A, Stancu I-C, Vasconcelos B et al (2017) Tau interactome mapping based identification of Otub1 as tau deubiquitinase involved in accumulation of pathological tau forms in vitro and in vivo. Acta Neuropathol 133(5):731-749. https://doi.org/10.1007/s00401-016-1663-9

83. Wirths O, Walter S, Kraus I, Klafki HW, Stazi M, Oberstein TJ et al (2017) Ntruncated A $A 4-x$ peptides in sporadic Alzheimer's disease cases and transgenic Alzheimer mouse models. Alzheimers. Res. Ther. Alzheimers Res Ther 9(1):80. https://doi.org/10.1186/s13195-017-0309-z

84. Wisniewski HM, Sadowski M, Jakubowska-Sadowska K, Tarnawski M, Weigiel J (1998) Diffuse, Lake-like amyloid-Beta deposits in the Parvopyramidal layer of the Presubiculum in Alzheimer disease. J Neuropathol Exp Neurol 57(7): 674-683

85. Wittnam JL, Portelius E, Zetterberg H, Gustavsson MK, Schilling S, Koch B et al (2012) Pyroglutamate amyloid $\beta(a \beta)$ aggravates behavioral deficits in transgenic amyloid mouse model for Alzheimer disease. J Biol Chem 287(11):8154-8162. https://doi.org/10.1074/jbc.M111.308601

86. Xue J, Dong JH, Huang GD, Qu XF, Wu G, Dong XR (2014) NF-kB signaling modulates radiation-induced microglial activation. Oncol Rep 31(6):25552560. https://doi.org/10.3892/or.2014.3144

87. Zhang XHF, Leslie CS, Chasin LA (2005) Computational searches for splicing signals. Methods 37(4):292-305. https://doi.org/10.1016/j.ymeth.2005.07.011 